\title{
Celastrol exerts a neuroprotective effect by directly binding to HMGB1 protein in cerebral ischemia-reperfusion
}

\author{
Dan-Dan Liu' ${ }^{1 \dagger}$, Piao Luo ${ }^{1 \dagger}$, Liwei Gu', Qian Zhang ${ }^{1}$, Peng Gao', Yongping Zhu' , Xiao Chen², Qiuyan Guo , \\ Junzhe Zhang ${ }^{1}$, Nan Ma ${ }^{1,3^{*}}$ and Jigang Wang ${ }^{1,4,5,6,7,8^{*}}$ (D)
}

\begin{abstract}
Background: Celastrol (cel) was one of the earliest isolated and identified chemical constituents of Tripterygium wilfordii Hook. f. Based on a cel probe (cel-p) that maintained the bioactivity of the parent compound, the targets of cel in cerebral ischemia-reperfusion (I/R) injury were comprehensively analyzed by a quantitative chemical proteomics method.
\end{abstract}

Methods: We constructed an oxygen-glucose deprivation (OGD) model in primary rat cortical neurons and a middle cerebral artery occlusion (MCAO) model in adult rats to detect the direct binding targets of cel in cerebral I/R. By combining various experimental methods, including tandem mass tag (TMT) labeling, mass spectrometry, and cellular thermal shift assay (CETSA), we revealed the targets to which cel directly bound to exert neuroprotective effects.

Results: We found that cel inhibited the proinflammatory activity of high mobility group protein 1 (HMGB1) by directly binding to it and then blocking the binding of HMGB1 to its inflammatory receptors in the microenvironment of ischemia and hypoxia. In addition, cel rescued neurons from OGD injury in vitro and decreased cerebral infarction in vivo by targeting HSP70 and NF-KB p65.

Conclusion: Cel exhibited neuroprotective and anti-inflammatory effects by targeting HSP70 and NF-KB p65 and directly binding to HMGB1 in cerebral I/R injury.

Keywords: Celastrol, Chemical proteomics, Target identification, High mobility group protein 1, Cerebral ischemiareperfusion

\section{Background}

Tripterygium wilfordii Hook. f. (TwHF)-based prescriptions have been widely used for the treatment of autoimmune diseases, tumors, and other diseases in China for centuries $[1,2]$. Of the many bioactive constituents isolated from Tripterygium wilfordii, celastrol (cel) has attracted close attention for more than 70 years because

\footnotetext{
*Correspondence: nanma927@126.com; jgwang@icmm.ac.cn

${ }^{\dagger}$ Dan-Dan Liu and Piao Luo contributed equally to this work.

1 Artemisinin Research Center, and Institute of Chinese Materia Medica, China Academy of Chinese Medical Sciences, Beijing 100700, China

Full list of author information is available at the end of the article
}

of its potential medicinal properties [3]. Cel exhibits diverse pharmacological effects over a wide range of disorders, such as cancer, diabetes, obesity [4], and neurodegenerative diseases [3]. Many studies have demonstrated the neuroprotective effects of cel in neurodegenerative diseases through its antioxidant activity and neuroinflammation attenuation capacity [5]. In addition, cel excellently relieved transient global cerebral ischemia and permanent cerebral ischemia induced injury by promoting microglia/macrophage M2 polarization [6], reducing the expression of p-JNK, p-c-Jun and NF-kB [7], and inhibiting the high mobility group box 1 (HMGB1)/ original author(s) and the source, provide a link to the Creative Commons licence, and indicate if changes were made. The images or other third party material in this article are included in the article's Creative Commons licence, unless indicated otherwise in a credit line to the material. If material is not included in the article's Creative Commons licence and your intended use is not permitted by statutory regulation or exceeds the permitted use, you will need to obtain permission directly from the copyright holder. To view a copy of this licence, visit http://creativecommons.org/licenses/by/4.0/. The Creative Commons Public Domain Dedication waiver (http://creativeco mmons.org/publicdomain/zero/1.0/) applies to the data made available in this article, unless otherwise stated in a credit line to the data. 
NF- $\mathrm{kB}$ signaling pathway to exhibit antiinflammatory and antioxidant actions in rats [8]. However, few have focused on determining whether cel has a neuroprotective effect against cerebral ischemia-reperfusion (I/R) injury or identifying its specific binding protein targets.

Neuroinflammatory processes have been implicated in the pathophysiology of multiple stages of cerebral I/R injury, and targeting neuroinflammation has always been an attractive treatment strategy for stroke [9]. Intensive studies of HMGB1, which is currently one of the crucial proinflammatory alarmins of stroke, in inflammationrelated diseases have been performed for a number of years. The nonhistone DNA binding protein HMGB1 is primarily located in the cell nucleus and has different biological functions according to the cellular location, binding receptors and redox states. HMGB1 shifts to the cytoplasm and extracellular space by activated immune cells or is passively released by necrotic or damaged cells, and it shows dynamic redox states due to distinct posttranslational modifications [10] and activated inflammatory immune reactions [11]. Outside of the cells, HMGB1 serves as a damage-associated molecular pattern (DAMP) or alarmin to mediate inflammation through receptors, including receptor for advanced glycation endproducts (RAGE) and Toll-like receptors 2 and 4 (TLR2, TLR4) [12]. HMGB1 constitutes three domains: the A box and B box (positively charged) domains and the carboxyl terminus (negatively charged) acidic tail. The three cysteines (Cys) located at positions 23, 45 (A box), and 106 (B box) mainly determine the redox states and physiological functions of HMGB1. Fully reduced HMGB1 isoform presents chemotaxis only by binding to CXCL12 and stimulates immune cell infiltration through the CXCR4 receptor in a collaborative manner. An intramolecular disulfide bond of HMGB1 in Cys 23 and 45 with critical Cys 106 in a reduced state has proinflammatory activity similar to that of cytokines via the TLR4/MD-2 complex, and it induces nuclear NF- $\mathrm{kB}$ translocation and produces tumor necrosis factor (TNF) in macrophages. Moreover, the chemotactic and cytokine activities disappear after all Cys are oxidized (sulfonyl HMGB1) [13, 14]. Therefore, the disulfide bond HMGB1 isoform is a biomarker of inflammation, which indicates that blocking the extracellular disulfide bond HMGB1 isoform may be a potential direction for the treatment of inflammation and immune-related diseases, including stroke.

Quantitative chemical proteomics technology based on small molecule compound probes and chemical labeling has been widely used to identify the targets and elucidate the mechanisms of natural and traditional medicines [15], including artemisinin [16], andrographolide [17], curcumin [18], and aspirin [19]. With the help of an activity-based cel probe (cel-p), tandem mass tag (TMT) labeling, liquid chromatography-tandem mass spectrometry (LC-MS/MS), and cellular thermal shift assay (CETSA), we elucidated the neuroprotective mechanisms and targets of cel in cerebral I/R injury and revealed that cel directly bound to HMGB1 to inactivate its cytokine activity and targeted HSP70 and NF- $\mathrm{kB}$ to exert anti-inflammatory activity.

\section{Materials and methods Animals}

All experiments were carried out for the sake of minimizing the number and suffering of animals. All animal experiment operations meet the requirements of the Beijing Administration Rule of Laboratory Animal and were approved by the Animal Experimental Ethics Review Committee of the Institute of Basic Research for Chinese Medicine, China Academy of Chinese Medical Sciences.

The neonatal Sprague-Dawley rats within $12 \mathrm{~h}$ of birth (Vital River Laboratories, Beijing, China) were used for primary cortical neurons isolation. Male adult Sprague-Dawley rats (260-280 g, Vital River Laboratories, Beijing, China) used for middle cerebral artery occlusion (MCAO) experiment were housed in a standard breeding environment without restriction to diet and drinking.

\section{Reagents}

Cell culture reagents: Dulbecco's modified Eagle medium (DMEM), sugar-free DMEM, DMEM/F-12 (1:1), and fetal bovine serum (FBS) were obtained from Corning, USA. Neurobasal-A medium, $50 \times$ B27 supplement, $100 \times$ penicillin-streptomycin (PS), $100 \times$ Glutamax-I, and $0.25 \%$ trypsin were purchased from Gibco, USA.

Click chemistry, pull-down, and LC-MS/MS reagents: $\mathrm{NaVc}, \mathrm{CuSO}_{4}$, TAMRA Azide, and Biotin Azide were obtained from Sigma, USA. High capacity neutravidin agarose resin, sequencing grade modified trypsin, $\mathrm{TMT}^{10}$ plex reagent set, Tetraethylammonium bromide (TEAB), and Pierce ${ }^{\mathrm{TM}}$ Quantitative Fluorometric Peptide Assay Kit were purchased from Thermo Fisher Scientific, USA. Oasis HLB Extraction Cartridge was obtained from Waters. THPTA was purchased from Click Chemistry Tools.

Other reagents: cel (HPLC >98\%), edaravone (eda) injection (Yangtze River Pharm; China), recombinant human HMGB1 protein (Abcam, USA), cell counting kit-8 (CCK-8; DOJINDO; Japan), and coomassie brilliant blue (CBB; Beyotime; China). The antibodies used in the experiments are shown in Table 1. All other reagents were purchased from Sigma without special instructions. 
Table 1 Primary antibodies

\begin{tabular}{llll}
\hline Primary antibodies & Host & Dilution ratio & Supplier \\
\hline MAP2 & Mouse & $1: 500(\mathrm{IF})$ & Abcam, United States \\
-tubulin & Rabbit & $1: 500(\mathrm{IF})$ & Abcam, USA \\
B-actin & Mouse & $1: 5000(\mathrm{WB})$ & Affinity Biosciences, USA \\
PCNA & Rabbit & $1: 3000(\mathrm{WB})$ & Proteintech Group, USA \\
NF-KB p65 & Mouse & $1: 1000(\mathrm{WB})$ & Proteintech Group, USA \\
& & $1: 500(\mathrm{IF})$ & \\
HSP70 & Rabbit & $1: 1000(\mathrm{WB})$ & Abcam, USA \\
& & $1: 500(\mathrm{IF})$ & \\
HMGB1 & Rabbit & $1: 1000(\mathrm{WB})$ & Abcam, USA \\
& & $1: 500(\mathrm{IF})$ & \\
RAGE & Rabbit & $1: 1000(\mathrm{WB})$ & Proteintech Group, USA \\
TLR4 & Rabbit & $1: 1000(\mathrm{WB})$ & Proteintech Group, USA \\
\hline
\end{tabular}

\section{Primary rat cortical neuron isolation and RAW 264.7 cell culture}

The neonatal Sprague-Dawley rats within $12 \mathrm{~h}$ of birth were used for primary neurons isolation as previously established with minor revision [20]. Briefly, the cortices of newborn rats were sterile separated in pre-cooling $\left(4{ }^{\circ} \mathrm{C}\right) \mathrm{DMEM} / \mathrm{F}-12$ (1:1). The minced cortex tissue was digested with $0.2 \mathrm{mg} / \mathrm{mL}$ DNase I and $2 \mathrm{mg} / \mathrm{mL}$ papain, and inactivated by adding $10 \%$ volume FBS. The cell suspension was washed twice with DMEM/F-12 (1:1) and resuspended in DMEM/F-12 (1:1) containing 10\% FBS and $1 \times$ PS. The cells suspension passed through 300 mesh sieves were seeded on L-polylysine pre-coated well plates or dishes and incubated at $37{ }^{\circ} \mathrm{C}$ in an incubator with $5 \%(\mathrm{v} / \mathrm{v}) \mathrm{CO}_{2}$. The DMEM/F-12 (1:1) was replaced with complete Neurobasal-A medium replenished with $1 \times \mathrm{PS}, 1 \times$ Glutamax-I, and $1 \times \mathrm{B} 27$ after seeding the cells $4-6 \mathrm{~h}$. The culture medium was changed half every 2-3 days, and all the experiments were carried out on the seventh day unless otherwise stated.

RAW 264.7 cells were cultured in DMEM containing $10 \%$ FBS, $1 \times$ PS, and maintained in a $37{ }^{\circ} \mathrm{C}$ incubator with $5 \%(\mathrm{v} / \mathrm{v}) \mathrm{CO}_{2}$. RAW 264.7 cells grown to $80-90 \%$ confluence were digested with $0.25 \%$ trypsin and passaged, and TNF- $\alpha$ was tested in cells within 20 passages.

\section{Oxygen glucose deprivation (OGD) insult}

The transient OGD model was constructed to simulate cerebral I/R injury in cultured primary neurons as previously described [21]. Briefly, the Neurobasal-A medium was displaced with deoxygenated, sugar-free DMEM, and the cells were incubated in a hypoxia chamber (STEMCELL Technologies, Canada) filled with 95\% $\mathrm{N}_{2}+5 \%$ $\mathrm{CO}_{2}$ for $4 \mathrm{~h}$ in a $37{ }^{\circ} \mathrm{C}$ incubator and returned to normal culture condition according to the experimental requirement. In contrast, control group cells were cultured in normal culture conditions. After reaching the established time, cell viability was determined by CCK-8 assay or cells were collected for other experiments. For the CCK-8 assay, absorbance was measured using a multimode plate reader (PerkinElmer, USA) at $450 \mathrm{~nm}$.

\section{Proteome reactivity profiles of primary neurons with cel-p} Labeling profiles of living primary neurons with cel-p were performed in the presence or absence of cel and OGD model by in-gel fluorescence scanning referred to the previous operations [22]. Similarly, different concentrations of cel-p $(0-1.6 \mu \mathrm{M}$ or $0.8 \mu \mathrm{M}$, dimethylsulfoxide (DMSO) never exceeded $1 \%$ in the final solution) in the absence or presence of competitor (cel, $2 \times, 4 \times$, $6 \times, 8 \times)$ were added into the 6 -well plates with or without OGD interfere and incubated for $4 \mathrm{~h}$ in a cell incubator. Then supernatant of cell lysate was collected, and the protein concentrations were determined by using the $\mathrm{BCA}$ protein assay (Pierce ${ }^{\mathrm{TM}} \mathrm{BCA}$ protein assay kit). The click chemistry reaction was performed with $\mathrm{NaVc}$ (100 mM stock solution, final concentration: $1 \mathrm{mM}$ ), THPTA (100 mM stock solution, final concentration: $100 \mu \mathrm{M}), \mathrm{CuSO}_{4}(100 \mathrm{mM}$ stock solution, final concentration: $1 \mathrm{mM})$, and TAMRA Azide $(5 \mathrm{mM}$ stock solution, final concentration: $50 \mu \mathrm{M}$ ) in equal amounts $(100 \mu \mathrm{g})$ of extracted protein for $2 \mathrm{~h}$ at room temperature (r.t.). The protein was then precipitated with $1 \mathrm{~mL}$ precooling $\left(-20{ }^{\circ} \mathrm{C}\right)$ acetone and redissolved with $30 \mu \mathrm{L}$ $1 \times$ SDS loading buffer. The samples $(15 \mu \mathrm{L})$ were separated with $10 \%$ sodium dodecyl sulfate-polyacrylamide gel electrophoresis (SDS-PAGE) gel, and the labeling profiles were visualized by in-gel fluorescence scanning in laser scanner (Azure Sapphire RGBNIR, USA) and then the gels were stained with CBB.

\section{Cellular imaging}

Cellular imaging experiments were carried out as described previously to verify the utility of cel-p for imaging of potential cellular targets [23]. To track the cellular locations of cel-p, living primary neurons were incubated with cel-p $0.8 \mu \mathrm{M}$ for $0-6 \mathrm{~h}$. The cells were fixed with $4 \%$ paraformaldehyde solution for $10 \mathrm{~min}$ and $0.2 \%$ Triton X-100 permeated for 15 min. Click chemistry reaction was carried out (regents and concentrations as described above) for $2 \mathrm{~h}$ and washed thrice to remove excessive agents. The cells were stained with Hoechst for $10 \mathrm{~min}$. DMSO-treated samples were used as control concurrently. Imaging was done with confocal fluorescence microscopy (Leica TCS SP8 SR, Germany).

For colocalization experiments, living primary neurons were incubated with DMSO, $0.8 \mu \mathrm{M}$ cel-p in the presence or absence of competitor $($ cel, $8 \times$ ) for $4 \mathrm{~h}$. 
The cells were fixed, permeated, carried out with click chemistry reaction, and washed as described above. The cells were incubated overnight at $4{ }^{\circ} \mathrm{C}$ with antiHMGB1 antibody and then with secondary fluorescence antibody (goat anti-rabbit, 1:500, Abcam) for $2 \mathrm{~h}$ at r.t.. The images were obtained with confocal fluorescence microscopy after staining with Hoechst for $10 \mathrm{~min}$.

\section{Pull-down/LC-MS/MS and target validation}

Pull-down/LC-MS/MS experiments were carried out to identify the interacting cellular targets of cel in primary neurons according to the previous description [24], with the following optimizations. The primary neurons were treated with the cel-p-containing medium $(4 \mu \mathrm{M})$ in the presence or absence of competitor (cel, $8 \times$ ) for $4 \mathrm{~h}$. Click chemistry reaction was carried out with Biotin Azide $(50 \mathrm{mM}$ stock solution, final concentration: $50 \mu \mathrm{M}$ ), NaVc, THPTA, and $\mathrm{CuSO}_{4}$ (concentrations as described above) in equal amounts $(1 \mathrm{mg})$ of extracted protein from each sample for $4 \mathrm{~h}$. The proteins were precipitated in pre-cooling $\left(-20{ }^{\circ} \mathrm{C}\right)$ acetone and redissolved with $0.1 \%$ SDS in PBS. The sample supernatants were poured into the washed agarose beads $(50 \mu \mathrm{L})$. Upon incubation with beads for $2 \mathrm{~h}$ at r.t., the beads were washed thrice with $1 \%$ SDS, $0.1 \%$ SDS, and $6 \mathrm{M}$ urea in order.

For digestion, the beads were resuspended in $500 \mu \mathrm{L}$ of $6 \mathrm{M}$ urea in PBS and $25 \mu \mathrm{L}$ of $200 \mathrm{mM}$ DTT in $25 \mathrm{mM}$ $\mathrm{NH}_{4} \mathrm{HCO}_{3}$ buffer. The reaction was incubated at $37{ }^{\circ} \mathrm{C}$ for $30 \mathrm{~min}$. Then, the Cys were blocked with $400 \mathrm{mM}$ iodoacetamide (IAA) in $6 \mathrm{M}$ urea and incubated for $45 \mathrm{~min}$ in the dark. Sequencing grade modified trypsin $(2 \mu \mathrm{g})$ was added into each sample and incubated overnight to digest the proteins captured on the beads. The supernatant containing digestive peptides was separated from the mixture by centrifugation and transferred to a new tube. After spin-dry, the dried samples were reconstituted with $100 \mathrm{mM}$ TEAB, and the digestive peptides were labeled with distinct $\mathrm{TMT}^{10}$ isobaric peptide tags subsequently on the basis of instructions. Two biological replicates were performed. TMT ${ }^{10}-126$ and $\mathrm{TMT}^{10}-131$ label reagents were labeled for negative control samples; $\mathrm{TMT}^{10}-129 \mathrm{C}$ and $\mathrm{TMT}^{10}-129 \mathrm{~N}$ were labeled for cel-ptreated samples; $\mathrm{TMT}^{10}-130 \mathrm{C}$ and $\mathrm{TMT}^{10}-130 \mathrm{~N}$ were labeled for cel-p-treated samples in the presence of cel, respectively. After incubation for $2 \mathrm{~h}$, the reaction was quenched with $1 \mathrm{M}$ Tris $\mathrm{HCl}$ and the labeled samples were converged to a single new tube. Upon extraction, the samples were desalted by $\mathrm{C} 18$ column and then submitted for LC-MS/MS analysis (Thermo Fisher, Orbitrap Fusion Lumos, USA).

\section{CETSA}

For CETSA, experiments were performed according to the previously published protocols with minor modifications [25]. The primary neurons in $100 \mathrm{~mm}$ dishes were collected with PBS containing protease inhibitor. The cells were subjected to freezing and thawing cycles in liquid nitrogen and repeated mechanical crushing to obtain cell lysate supernatant by centrifugation. Then equivalent supernatant proteins $(1 \mathrm{mg})$ were treated with either DMSO or cel $(20 \mu \mathrm{M}) 1 \mathrm{~h}$ with gentle shaking at r.t.. The treated supernatant was divided into 10 equal parts and heated according to designated temperatures. The cooled samples were centrifugated again to obtain supernatant and to perform Western blotting (WB) analysis.

\section{WB analysis}

Supernatants of neuron lysate or rats cerebral cortex tissues lysate were obtained with RIPA lysate in the presence of protease inhibitor. For the cytoplasm and nuclear protein extraction, the nuclear-cytosol extraction kit was used on the basis of instructions. Fully reduced and disulfide bond HMGB1 isoforms were detected in primary neurons and condensed culture supernatant with nonreducing PAGE gel, and samples were collected avoiding the use of reducing agents $(\beta$-mercaptoethanol or DTT). After OGD- and cel-treatments as detailed above, the culture supernatant was collected at $0 \mathrm{~h}, 4 \mathrm{~h}$, $8 \mathrm{~h}, 12 \mathrm{~h}, 24 \mathrm{~h}$, and $48 \mathrm{~h}$ and centrifuged to discard cell debris. Then, the supernatant was concentrated 20 folds with Amicon Ultra-4 $50 \mathrm{kDa}$ and Amicon Ultra-4 $10 \mathrm{kDa}$. The protein concentrations were determined by using the BCA protein assay, and the denatured samples were separated with $10 \%, 12 \%$, or $15 \%$ SDS-PAGE gel.

Separated protein samples were transferred to PVDF membranes, blocked in $5 \%$ bovine serum albumin (BSA), and incubated overnight at $4{ }^{\circ} \mathrm{C}$ with anti-HMGB1, antiHSP70, anti-NF- $\mathrm{KB}$ p65, anti-RAGE, anti-TLR4, PCNA, or $\beta$-actin primary antibodies and then with secondary antibodies (goat anti-rabbit, 1:5000; goat anti-mouse, 1:5000) for $2 \mathrm{~h}$ at r.t. Membranes were washed thrice with TBST after incubation. The bands were visualized with enzyme-linked chemiluminescence in the detection system (Azure C400, USA).

\section{Immunofluorescence (IF) staining}

For IF in paraffin sections of rat brain tissue, the paraffin slices were experienced a series of dewaxing and dehydration. The slices were incubated in antigen retrieval for $10 \mathrm{~min}$ in $95^{\circ} \mathrm{C}$ and permeabilized $15 \mathrm{~min}$ in $0.2 \%$ Triton $\mathrm{X}-100$. The slices were blocked in 5\% BSA for $1 \mathrm{~h}$, incubated with primary antibodies against HMGB1, HSP70, or NF- $\mathrm{kB}$ p 65 at $4{ }^{\circ} \mathrm{C}$ overnight and $2 \mathrm{~h}$ with secondary 
fluorescence antibodies (goat anti-rabbit, 1:500; goat anti-mouse, 1:500, Abcam) in the dark. After 10 min of Hoechst staining, the slices were photographed with a laser scanning confocal microscope.

For IF in primary neurons, the treated cells were washed with PBS, then fixed in $4 \%$ paraformaldehyde solution, and permeabilized in $0.2 \%$ Triton $\mathrm{X}-100$. The rest procedures were the same with IF processes in rats.

\section{Expression and purification of HMGB1 A box and B box}

Recombinant human HMGB1 A box (residues 1-89) and B box (residues 90-175) were cloned in a modified pET-24d vector (Novagen, Madison, WI) expressing a protein with an $\mathrm{N}$-terminal 6-His tag. The Escherichia coli BL21 was transformed with pET24d-HMGB1 A box and pET24d-HMGB1 B box, cultured in LB medium containing $50 \mathrm{~g} / \mathrm{mL}$ kanamycin at $37{ }^{\circ} \mathrm{C}$ to an absorbance of 0.8 at $600 \mathrm{~nm}$, and expression was induced with $0.4 \mathrm{mM}$ Isopropyl-D-1-thiogalactopyranoside (IPTG) for $12 \mathrm{~h}$ at $16{ }^{\circ} \mathrm{C}$ before being harvested by centrifugation. Cell pellets were suspended in lysis buffer $(20 \mathrm{mM}$ Tris- $\mathrm{HCl}$, pH 8.0, $200 \mathrm{mM} \mathrm{NaCl}, 1 \mathrm{mM}$ PMSF) and disrupted by sonication. After centrifugation $\left(12,000 \mathrm{~g}, 30 \mathrm{~min}, 4{ }^{\circ} \mathrm{C}\right)$, the supernatant incorporated His-tagged recombinant A box or B box was applied to a Ni-beads column. The column was washed with $30 \mathrm{~mL}$ binding buffer $(20 \mathrm{mM}$ Tris- $\mathrm{HCl}, \mathrm{pH} 8.0,200 \mathrm{mM} \mathrm{NaCl}$ and $20 \mathrm{mM}$ or $50 \mathrm{mM}$ Imidazole). A box protein was eluted with elution buffer (20 mM Tris-HCl, pH 8.0, $200 \mathrm{mM} \mathrm{NaCl}$ and $200 \mathrm{mM}$ Imidazole). B box protein was eluted with elution buffer (20 mM Tris-HCl, pH 8.0, $200 \mathrm{mM} \mathrm{NaCl}$ and $100 \mathrm{mM}$ Imidazole). The samples were exchanged by the buffer containing $20 \mathrm{mM}$ Tris- $\mathrm{HCl}, \mathrm{pH} 8.0$, and $200 \mathrm{mM} \mathrm{NaCl}$ and concentrated by using centrifugal filter units according to the protocol provided by the manufacturer. The concentration of purified proteins was determined by BCA protein assay reagent kit. The purity and integrity of purified HMGB1 A box and B box were verified by CBB after 15\% SDS-PAGE gel separation.

\section{HMGB1 full-length protein, A box and B box labeling and activity assays}

Briefly, recombinant human HMGB1 full-length protein, A box and B box were dissolved or diluted with PBS and reacted with cel, cel-p, IAA, N-Hex-5-ynyl-2-iodoacetamide (IAA-yne), glycyrrhetinic acid (GA), metformin (Met) or DTT as needed for a period of time. Subsequently, the click chemistry reaction was conducted as same as the above fluorescence labeling, and the proteins were separated with $12 \%$ (HMGB1 full-length protein) or 15\% SDS-PAGE gel (A box and B box). The labeling states were visualized by a fluorescence laser scanner and stained with CBB.
To detect the effect of cel on the proinflammatory activity of recombinant human HMGB1 protein, HMGB1 protein and cel combined HMGB1 protein complex activities were measured by testing the TNF- $\alpha$ content in RAW 264.7 cells after $24 \mathrm{~h}$ of treatment. To confirm whether cel blocked the binding of receptors TLR4 and RAGE to B box, the precipitation of B box-cel complex experiment was conducted as described previously with minor revisions [26]. Briefly, B box proteins $(100 \mu \mathrm{g})$ were first reacted with or without an equivalent amount of cel (equimolar with B box, $10^{-2} \mu \mathrm{mol}$ ) or five-folds amount of cel $\left(5 \times 10^{-2} \mu \mathrm{mol}\right)$ in Ni-beads column for $1 \mathrm{~h}$. Then $500 \mu \mathrm{g}$ lysate of primary neurons was added into the $\mathrm{Ni}$ beads column and reacted for $2 \mathrm{~h}$ at $4{ }^{\circ} \mathrm{C}$ and eluted to precipitate B box or B box-cel complex. The denatured samples were subjected to WB analysis with antibodies against TLR4 and RAGE. The same B box with an equivalent amount of cel elution without incubation with cells lysate was used for TNF- $\alpha$ analysis in RAW 264.7 cells to research whether cel reduced the ability of B box to induce TNF- $\alpha$ secretion.

\section{Induction of MCAO and neurological defect assessment in rats}

By inserting a filament to occlude the right middle cerebral artery (MCA) of male Sprague-Dawley rats (250$280 \mathrm{~g}$ ), we established the cerebral I/R model in vivo as described previously [27]. Briefly, the rats fasted overnight were anesthetized with a continuous supply of $3 \%$ isoflurane/95\% oxygen mixture through a rat mask. After cutting a $2-\mathrm{cm}$ long longitudinal incision in the neck, the internal carotid artery (ICA), external carotid artery (ECA) and common carotid artery (CCA) on the right side of the rats were carefully separated with forceps. The ECA was ligated and burned at the distal end of the bifurcation. Temporary occlusion of CCA and ICA with artery clamps, and a $0.36-\mathrm{mm}$ monofilament (2636A4, Beijing Xinong Technology Co., Ltd, China) was inserted into the ICA through a tiny incision in the ECA and advanced approximately $18 \mathrm{~mm}$ until slight resistance was felt to block the cerebral blood flow of rats MCA. The rats were anesthetized again $90 \mathrm{~min}$ later and the filaments were withdrawn to resume blood stream providing. The rats of the sham group underwent the same steps without inserting the filament. Rats in model $(\mathrm{M})+$ cel group were administered with $1 \mathrm{mg} / \mathrm{kg}$ cel, and rats in $\mathrm{M}+$ eda group administered with $6 \mathrm{mg} / \mathrm{kg}$ eda via caudal vein were used as positive control according to the previously research [6, 28]. For intraperitoneal injection (i.p.), cel was dissolved in $1 \%$ DMSO and $0.9 \%$ physiological saline in order to yield a concentration of $1 \mathrm{mg} / 3 \mathrm{~mL}$. The cel and eda were given once at $0 \mathrm{~h}, 24 \mathrm{~h}$, and $48 \mathrm{~h}$ 
after cerebral I/R, respectively. Four groups included (1) sham, physiological saline i.p.; (2) M, physiological saline i.p.; (3) $\mathrm{M}+$ cel $1 \mathrm{mg} / \mathrm{kg}$, i.p.; and (4) M+eda $6 \mathrm{mg} / \mathrm{kg}$, intravenous injection (i.v.).

The neurological deficits of rats were assessed at $24 \mathrm{~h}, 48 \mathrm{~h}$, and $72 \mathrm{~h}$ after reperfusion, respectively, by an experimenter in a blinded experiment. ZeaLonga 5-point scores were used to assess neurologic deficits according to the previous descriptions [27]. Briefly, 0 score indicates no obvious neurological deficit; 1 score indicates left forepaw not fully extended; 2 score indicates the body of the rat circled to the left; 3 score indicates circling around and falling to the left; 4 score indicates unable walk spontaneously and loss of consciousness; and 5 score indicates death. The animals without symptoms of neurological impairment ( 0 score) or dying ( 5 score) after surgery were rejected. The animals compatible with requirement were divided into three groups for physiological saline, cel, and eda intervention using a simple random sampling method. Infarct volume was determined by 2, 3 , 5 -triphenyltetrazolium chloride (TTC) stating and calculated with Image J software as previously [27] $72 \mathrm{~h}$ after reperfusion. Briefly, the percentage of the infarct volume $=$ the infarct volumes (white parts)/the whole volume of the cortex. Nissl-stained cells in the rats cerebral cortex were observed at $200 \times$ magnifications with a light microscope to assess Nissl body damage.

\section{Statistical analysis}

Data were presented as the mean \pm SEM. Raw data were statistically analyzed with Graph Pad Prism 5.0. The density of WB bands was quantified using Image J software. The data were analyzed using one-way ANOVA. Fisher's least-significant difference post hoc test was used to test the differences between two groups. The $p$ values less than 0.05 were considered as statistically significant.

\section{Results}

\section{Cel and cel-p showed similar neuroprotective effects} in vitro

Cel-p was synthesized with an alkynyl handle to the carboxyl terminus of cel (Fig. 1A). We first detected the cytotoxicity of cel and cel-p in living primary neurons. As shown in Fig. 1B, the half maximal inhibitory concentration $\left(\mathrm{IC}_{50}\right)$ results suggested that cel-p closely mimicked the original compound in biological activity (cel $\mathrm{IC}_{50}=2.06 \pm 0.52 \mu \mathrm{M}$, cel-p $\mathrm{IC}_{50}=2.24 \pm 0.59 \mu \mathrm{M}$ ). For the cell viability assay, primary neurons were incubated in 96-well plates for 7 days and then cultured in

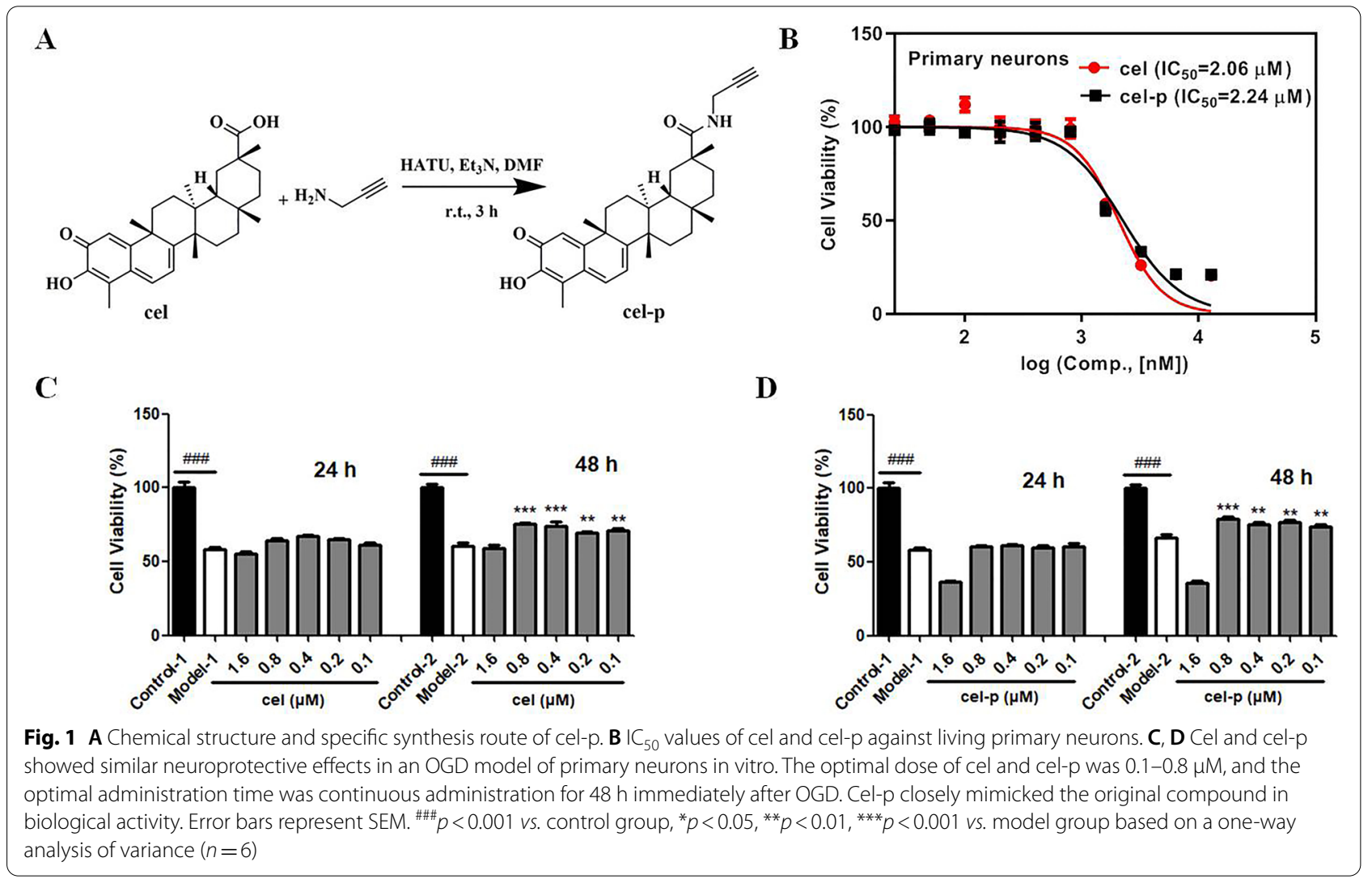


an experienced OGD model to evaluate the neuroprotective effect of cel and cel-p. As shown in Fig. 1C, cel exhibited an obvious neuroprotective effect in the OGD model of primary neurons. The optimal dose of cel was 0.1-0.8 $\mu \mathrm{M}$, and the optimal administration time was continuous administration for $48 \mathrm{~h}$ immediately after OGD. Cel-p showed a similar neuroprotective effect as cel (Fig. 1D). Therefore, cel retained its biological activity after introducing biorthogonal reaction groups.

\section{Cel significantly decreased pathological changes in MCAO rats}

Previous studies indicated that cel reduced the neurological deficits, brain water content, and infarct volume in a rat permanent cerebral ischemia model $[6,7]$. Therefore, we mainly evaluated whether cel exhibited a neuroprotective effect against rats cerebral I/R injury. The TTC staining and quantitative analysis results indicated that cel and eda significantly decreased the infarct volume (Fig. 2A, B, p < 0.001) compared with the model group. According to the Zea-Longa score results, cel and eda notably improved the behavior indexes (Fig. $2 \mathrm{C}, \mathrm{p}<0.01$ ) at $24 \mathrm{~h}, 48 \mathrm{~h}$, and $72 \mathrm{~h}$, while significant improvements were not observed in the neurological function of the model group. Moreover, the cel and eda treatments reduced the pathological changes in the cortex of MCAO rats compared with the model group, as shown by Nissl staining (Fig. 2D, E). Therefore, the neuroprotective effect of cel appeared to be similar to eda in vivo.

\section{Cel-p possessed high bioconjugation efficiency}

We evaluated the labeling profiles of cel-p in living primary neurons. As shown in Fig. 3A, cel-p showed strong labeling efficiency and concentration-dependent labeling of living primary neurons and produced obviously visible bands at probe concentration as low as $0.8 \mu \mathrm{M}$ after $4 \mathrm{~h}$ of incubation. As shown in Fig. 3B, the labeling profiles of cel-p $(0.8 \mu \mathrm{M})$ became weaker in the presence of the cel competitor $(1.6-6.4 \mu \mathrm{M})$, suggesting that cel-p bound similar intracellular targets to cel. Cellular imaging experiments with click chemistry reactions were performed to study the cellular locations of cel-p in living cells. As exhibited in Fig. 3C, cel-p mainly localized in the cytoplasm within $2 \mathrm{~h}$ and then gradually entered the nucleus, indicating that cel-p was able to label cytoplasm and nuclear proteins after $4 \mathrm{~h}$ of labeling. These data demonstrated that cel-p possessed high bioconjugation efficiency under in situ conditions and was a suitable substitute for cel for subsequent chemical proteomics procedures.

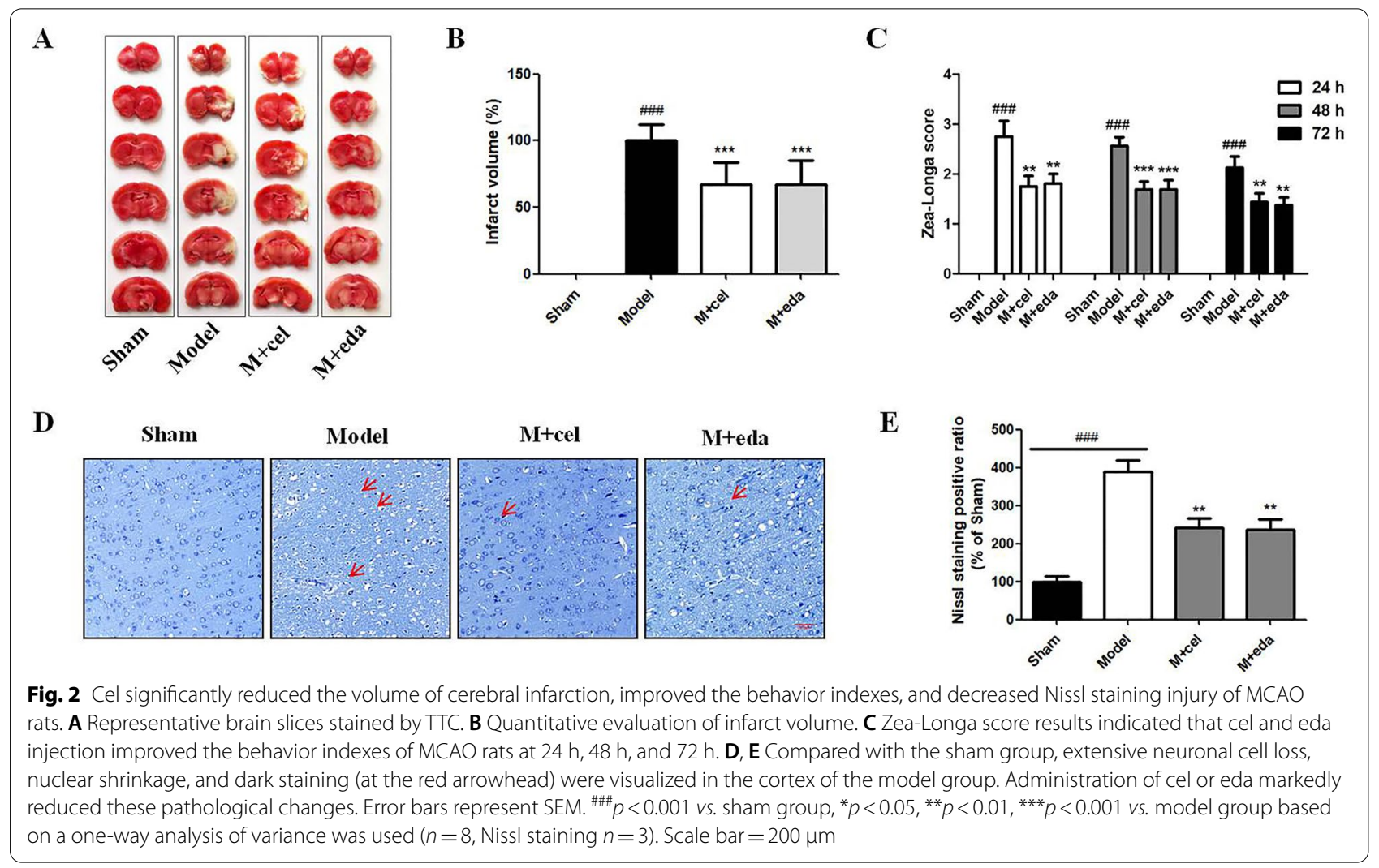




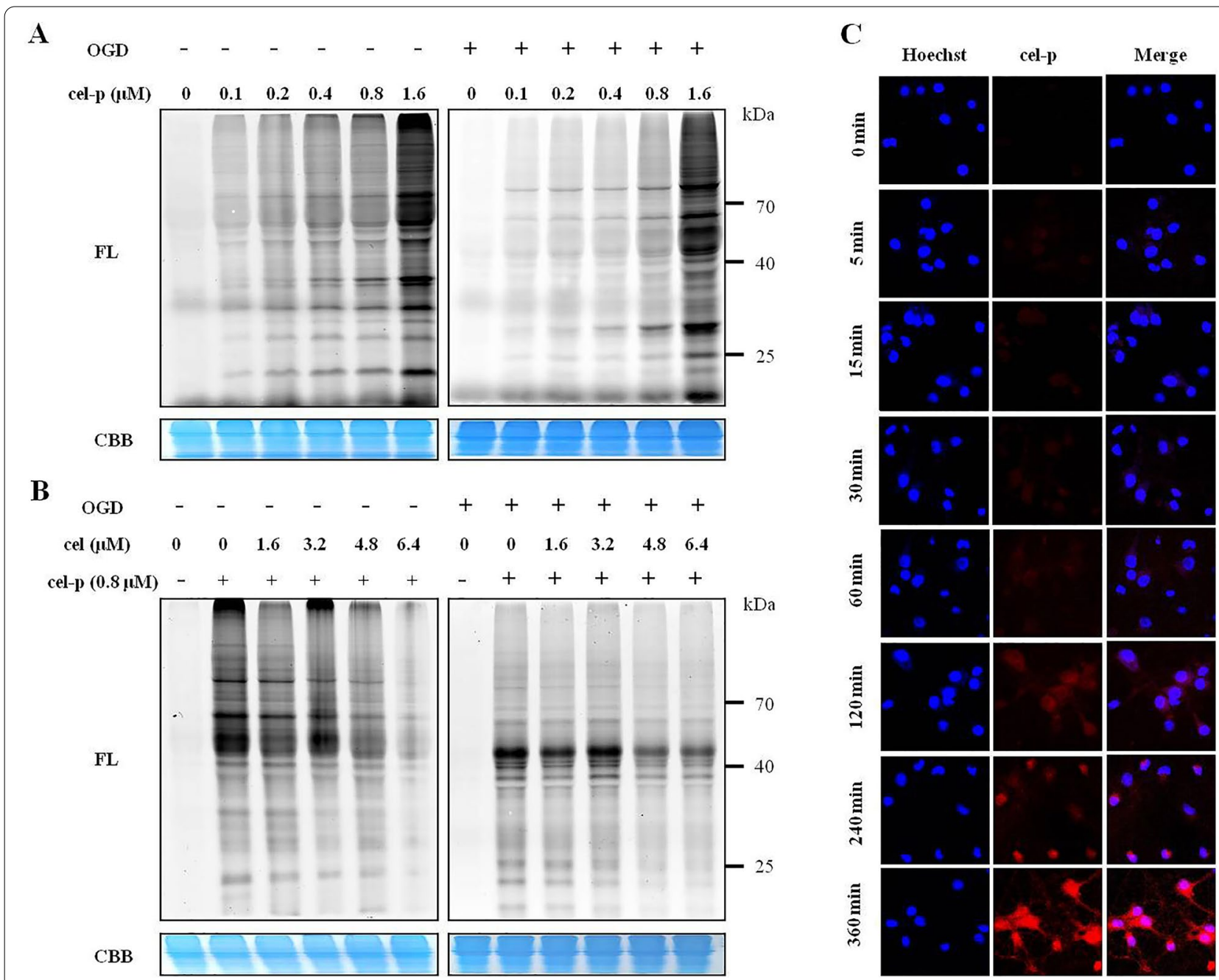

Fig. 3 Labeling profiles of cel-p in living primary neurons. A Concentration-dependent (0-1.6 $\mu$ M) labeling profiles of cel-p in normal and OGD injury primary neurons. B Competitive labeling profiles of cel-p $(0.8 \mu \mathrm{M})$ in normal and OGD injury primary neurons in the presence of cel $(2 \times, 4 \times$ $6 \times, 8 \times)$. C Cel-p mainly localized in the cell cytoplasm within $2 \mathrm{~h}$ and gradually entered the cell nucleus after $2 \mathrm{~h}$. FL, in-gel fluorescence scanning; $\mathrm{CBB}$, coomassie brilliant blue gel

\section{Cel directly targeted HMBG1 and did not affect the expression of HMGB1}

Next, we proceeded to identify the cellular targets of cel by quantitative chemical proteomics technology. Proteins with an enrichment ratio $R_{(\text {(cel-p/cel-p }+8 \times \text { cel) }}>1.5$ and $p<0.05$ were set as significant hits, and the protein information labeled by cel-p under this standard was analyzed. The identified protein hits were systematically analyzed and displayed by corresponding volcano plots after cel-p $(4 \mu \mathrm{M})$ with or without cel $(8 \times, 32 \mu \mathrm{M})$ treatment for $4 \mathrm{~h}$. A total of 1405 proteins were identified by the cel-p target recognition experiment, and 120 of these proteins were highly reliable. A complete list of identified proteins is provided in Table S1. According to these criteria, HMGB1 was identified as one of the direct binding proteins of cel. This identification has fairly high credibility because HMGB1 is currently one of the crucial proinflammatory alarmins of stroke (Fig. 4A). Primary neurons pull-down, WB, and IF assays verified that cel $(8 \times, 32 \mu \mathrm{M}$ or $6.4 \mu \mathrm{M})$ could completely compete for the binding of cel-p to HMGB1, further demonstrating that HMGB1 was a direct binding protein of cel (Fig. 4B-D). The CETSA results also proved the direct binding of cel and HMGB1 to decrease HMGB1 protein degradation with increasing temperature compared with the control group (Fig. 4E, F).

As shown in Fig. 4C, D, the HMGB1 protein in the celtreated $(8 \times, 6.4 \mu \mathrm{M})$ group was almost invisible. To confirm whether high concentrations of cel or cel-p affected the expression of HMGB1 in primary neurons, we treated normal living primary neurons with high concentrations of cel $(20 \mu \mathrm{M}$ and $40 \mu \mathrm{M})$ for $5 \mathrm{~h}$ to evaluate its 
effect on HMGB1 expression by WB. In the OGD model, we also examined the effect of cel-p $(4 \mu \mathrm{M})$ in the presence or absence of cel $(8 \times, 32 \mu \mathrm{M})$ on HMGB1 expression in neuronal cell lysates or living neuronal cells. As shown in Fig. 4G, high concentrations of cel or cel-p did not decrease the expression of HMGB1. We speculated that the mechanism of action was the occupation of the binding sites of HMGB1 by high concentrations of cel, which led to the failure of the HMGB1 protein to bind to the HMGB1 antibody, rather than the degradation of HMGB1 by high concentrations of cel or cel-p. In addition, we confirmed that cel had no effect on HMGB1 expression in normal primary neurons at a certain dose and time range (Fig. $4 \mathrm{H}-\mathrm{K}$ ). Unexpectedly, we did not observe a time-dependent increase of HMGB1 expression in the OGD model group. In contrast, the expression of HMGB1 in the model and $\mathrm{M}+$ cel groups decreased in a time-dependent manner (Fig. 4L-N). In conclusion, cel directly targeted HMGB1 and did not affect the expression of HMGB1.

\section{Cel exerted a neuroprotective effect through HSP70 and NF-kB p65}

As mentioned above, we did not find that cel affected the expression of HMGB1 in primary neurons with or without OGD insult. Previous studies showed that cel induced the HSP70 response and suppressed NF- $\mathrm{KB}$ activation to inhibit inflammatory responses and regulate the innate immune response [29-31]. Therefore, we established an OGD model in vitro and a MCAO model in vivo to mimic cerebral $I / R$ injury and tested whether cel affected the distribution changes of HMGB1 in the cytoplasm and nucleus and the expression changes of HSP70 and NF-kB p65 proteins. We found that the expression of HMGB1 in the cytoplasm of the model and $\mathrm{M}+$ cel groups significantly increased while the expression of HMGB1 in the nucleus obviously decreased (Fig. 5A-F). In summary, the overall HMGB1 expression was barely affected by cel, which had a limited effect on the distribution of HMGB1 in the cytoplasm and nucleus $48 \mathrm{~h}$ after OGD injury. In contrast, cel significantly increased the overall and nuclear expression of HSP70 and decreased the overall and nuclear expression of NF-kB p65 (Fig. 5A-F), which was consistent with the results of previous studies [29-31]. The IF results were in line with the WB results in vitro (Fig. 5J). Similar WB and IF results were also observed in the MCAO rats (Fig. $5 \mathrm{H}-\mathrm{N}$ ). Compared with the model group, cel $(1 \mathrm{mg} / \mathrm{kg})$ remarkably increased the expression of HSP70, downregulated the expression of NF- $\mathrm{kB}$ p65, and had no effect on the expression of HMGB1 (Fig. $5 \mathrm{H}-\mathrm{N}$ ) in the rats MCAO model. On the whole, cel exerted a neuroprotective effect through increasing the expression of HSP70 and decreasing the expression of NF-kB p65.

\section{Cel did not affect the secretion and redox states of HMGB1} HMGB1 in the concentrated supernatant of the primary neurons OGD model group increased gradually in a time-dependent manner and reached a peak at $24 \mathrm{~h}$ (Fig. 6A). The secreted HMGB1 in the model and $\mathrm{M}+\mathrm{cel}(0.8 \mu \mathrm{M})$ groups at $48 \mathrm{~h}$ were almost the same (Fig. 6B), which indicated that cel did not affect the secretion of HMGB1 after OGD injury. HMGB1 in the concentrated supernatant was actively secreted in response to OGD injury at $48 \mathrm{~h}$. Cel hardly affected the redox states of HMGB1, which presented as the disulfide bond HMGB1 isoform showed a faster mobility in nondenaturing page gel and cel did not affect its mobility (Fig. 6C). In addition, the disulfide bond but not the fully reduced HMGB1 isoform occupied the vast majority of the model and $M+$ cel groups in primary neurons injured by OGD compared with the control group (Fig. 6D). According to the present results, cel did not affect the secretion and expression of HMGB1 protein or affect the redox states of HMGB1. As shown in Fig. 6E, HMGB1 includes two DNA binding domains (A, B box) and an acidic C-terminal tail. Three Cys residues (Cys 23, 45 and 106) in the A and B boxes mainly determined the redox states of HMGB1. The disulfide bond between Cys 23 and Cys 45 and reduced Cys 106 is indispensable for the binding of HMGB1 to TLR4 and cytokine-inducing activity [10]. Hence, we focused on whether cel bound to HMGB1 to weaken its cytokine activity.

\section{Cel directly bound to HMGB1, HMGB1 A box, and B box \\ Cel exhibited strong combining ability with recombinant human HMGB1 protein in a}

\footnotetext{
(See figure on next page.)

Fig. 4 A Quantitative mass spectrometry-based profiling of cel-p $(4 \mu M)$ in the presence of excess cel $(8 \times, 32 \mu M)$. HMGB1 protein had a high degree of credibility. B-D Target validation of HMGB1 by pull-down, WB, and IF assays in living primary neurons under normal or OGD conditions verified that $8 \times$ cel could completely compete the binding of cel-p to HMGB1 protein. E, F CETSA results demonstrated that cel directly bound to HMGB1 protein to decrease protein degradation with increasing temperature. $\mathbf{G}$ High concentrations of cel or cel-p did not affect the expression of HMGB1 in primary neurons lysate or living neuronal cells within $5 \mathbf{~ h . ~} \mathbf{H}-\mathbf{K}$ Cel had no effect on HMGB1 expression in normal primary neurons within $48 \mathrm{~h}$ at $0.1-0.8 \mu \mathrm{M}$. L-N HMGB1 levels were decreasing with time in the $\mathrm{M}$ and $\mathrm{M}+$ cel groups. Error bars represent SEM. ${ }^{\#} p<0.05 \mathrm{vs}$. control group based on a one-way analysis of variance was used $(n=6)$. Scale bar $=25 \mu \mathrm{m}$
} 
A
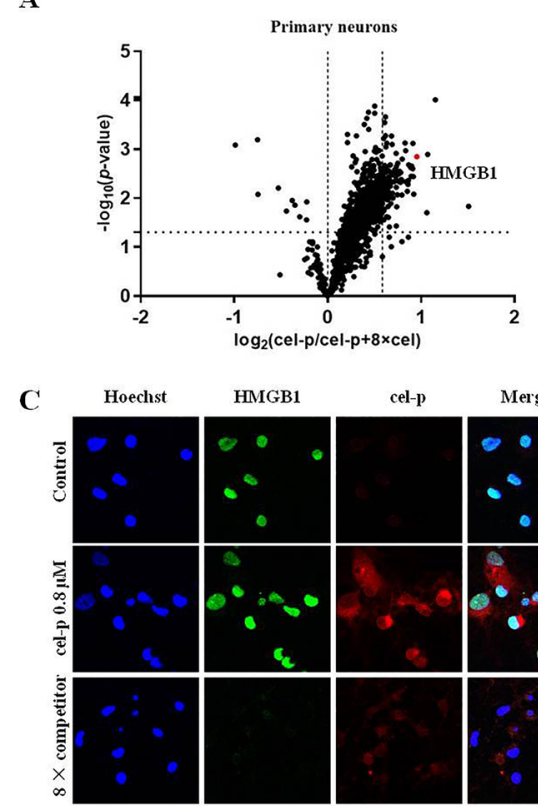

D

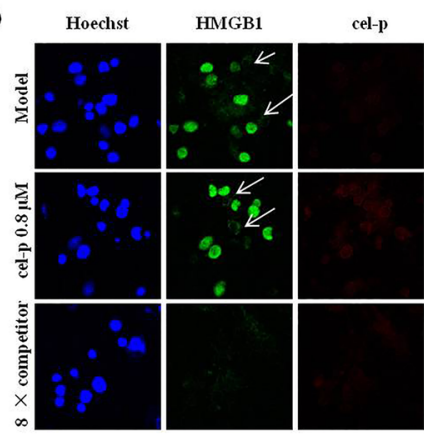

H

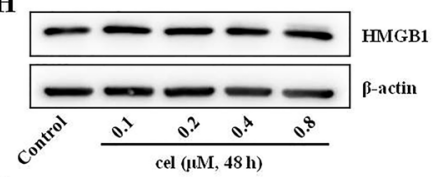

I
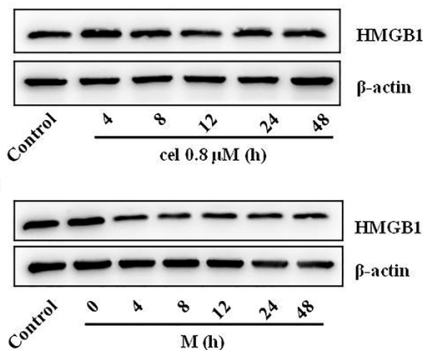

M

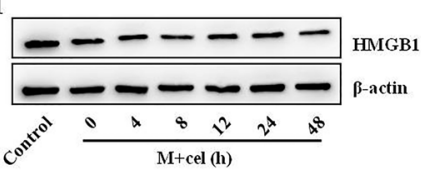

$\mathbf{J}$

N
B

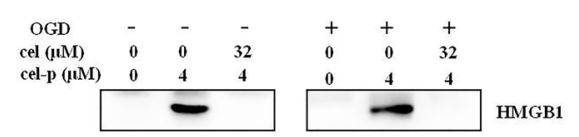

E

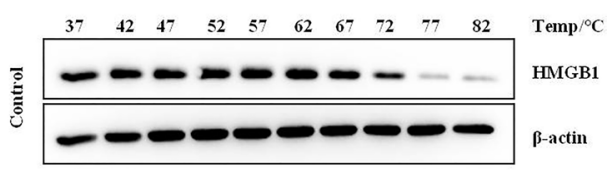

产

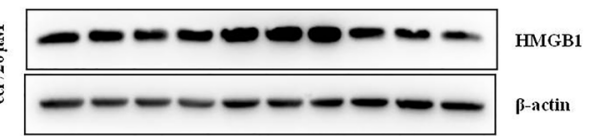

F

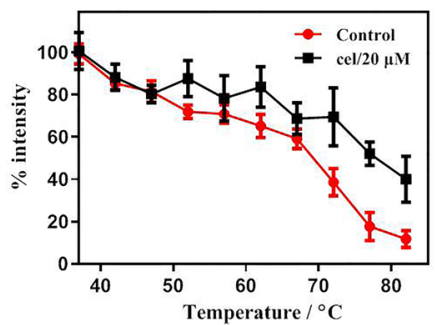

G
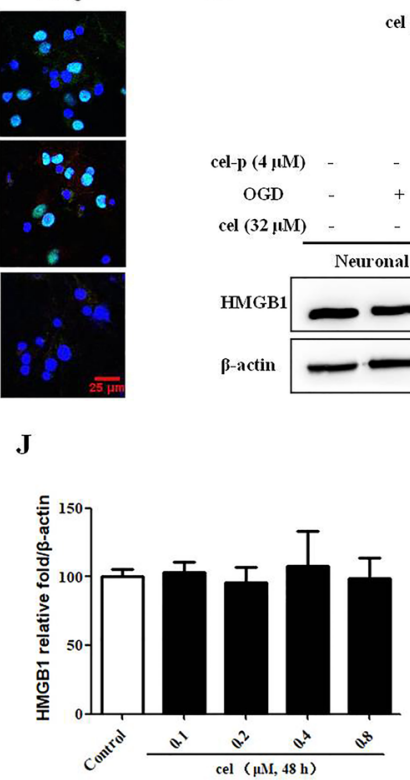

$\mathbf{K}$
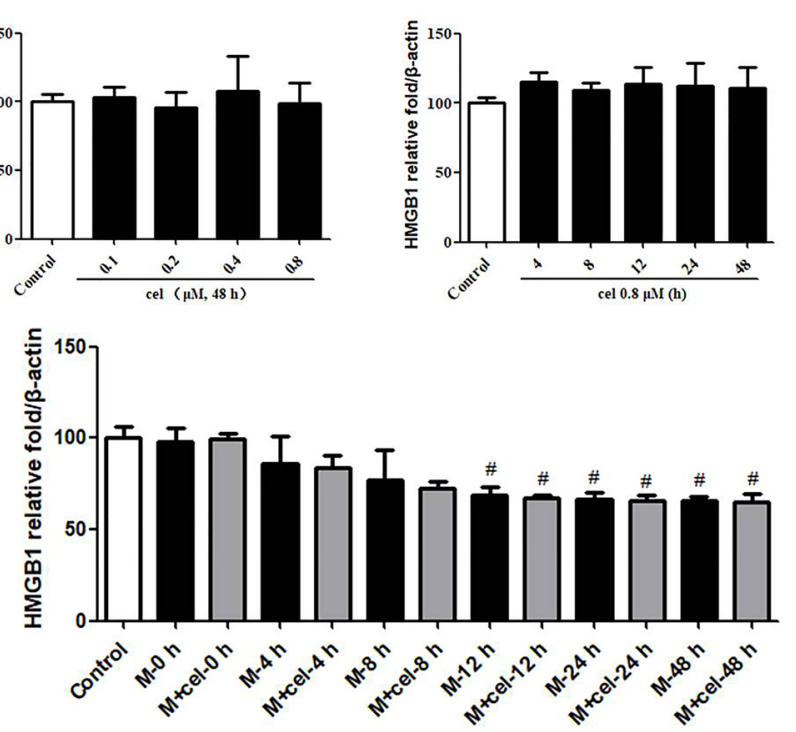

Fig. 4 (See legend on previous page.) 


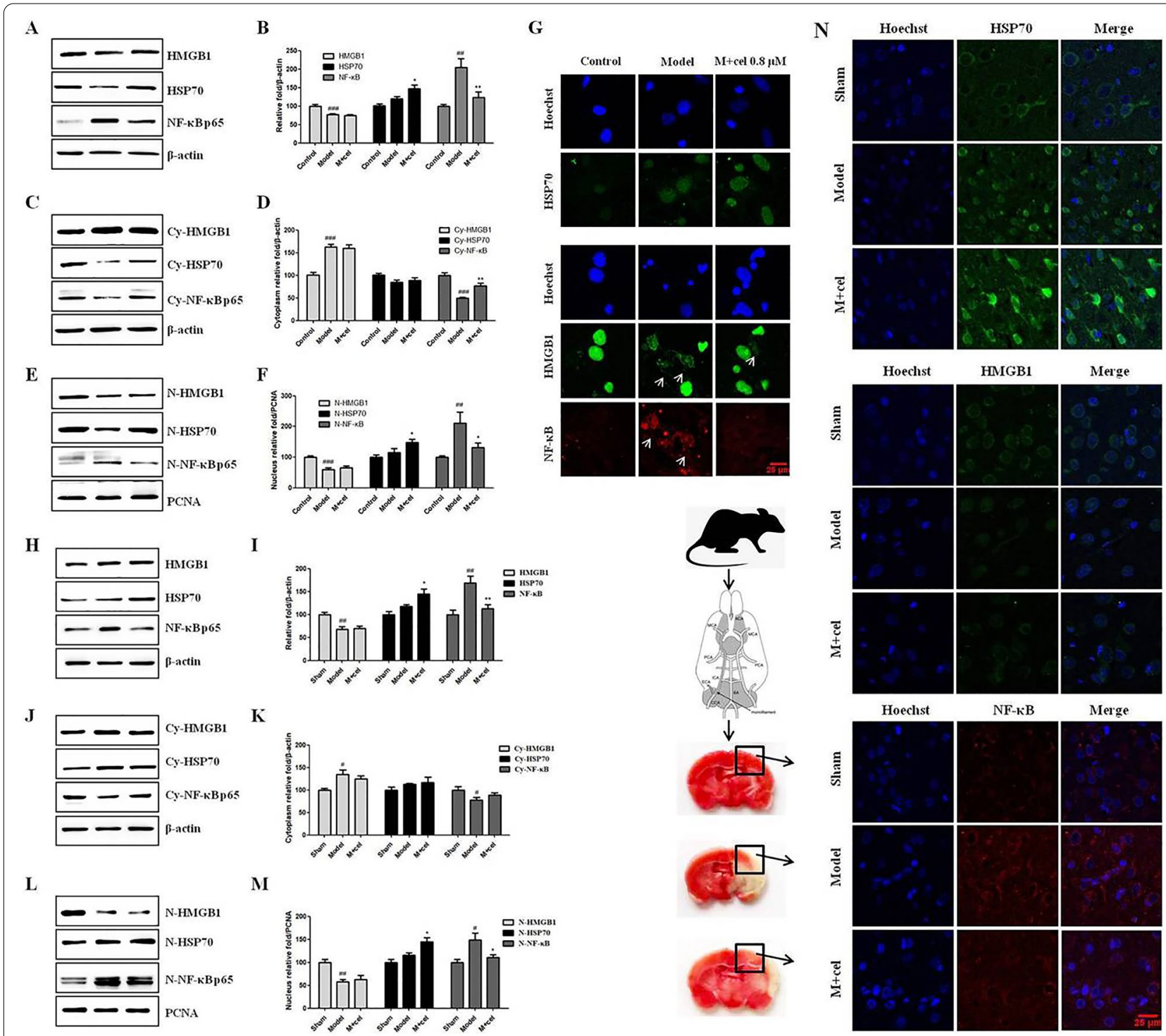

Fig. 5 A-J Changes of HMGB1, HSP70, and NF-KB p65 levels affected by cel under the OGD model were observed at $48 \mathrm{~h}$ by WB and IF in vitro. H-N Changes in HMGB1, HSP70, and NF-KB p65 levels were observed in the rat cerebral cortex by WB and rat cerebral cortex slices by IF. Error bars represent SEM. ${ }^{\# \# \#} p<0.001$ vs. control group (in vitro) or sham group (in vivo), ${ }^{*} p<0.05,{ }^{* *} p<0.01,{ }^{* * *} p<0.001$ vs. model group based on a one-way analysis of variance was used $(n=4)$. Scale bar $=25 \mu \mathrm{m}$

concentration-dependent manner (Fig. 7A, B). Cel almost completely competed for the binding of IAAyne to HMGB1 or DTT reduced HMGB1 (Fig. 7C, D), which indicated that cel could occupy Cys 106 of disulfide bond HMGB1 isoform or Cys 23, 45, 106 of fully reduced HMGB1 isoform. This result was consistent with previous studies showing that cel could exert cellular effects by forming covalent adducts with Cys residues of proteins [32-34]. The binding ability of cel to the HMGB1 protein was stronger than that of
GA and Met, which are recognized HMGB1 inhibitors that bind to the $\mathrm{A}$ and $\mathrm{B}$ boxes and the $\mathrm{C}$-terminal acidic tail of HMGB1, respectively (Fig. 7E, F). Cel also almost completely blocked the binding of IAA-yne to the Cys group of recombinant human HMGB1 A and $\mathrm{B}$ boxes. The binding of cel-p to the A and B boxes could not be blocked by IAA (Fig. 7G), which indicated that cel could bind to other sites of HMGB1 in addition to Cys 23, 45 and 106. 


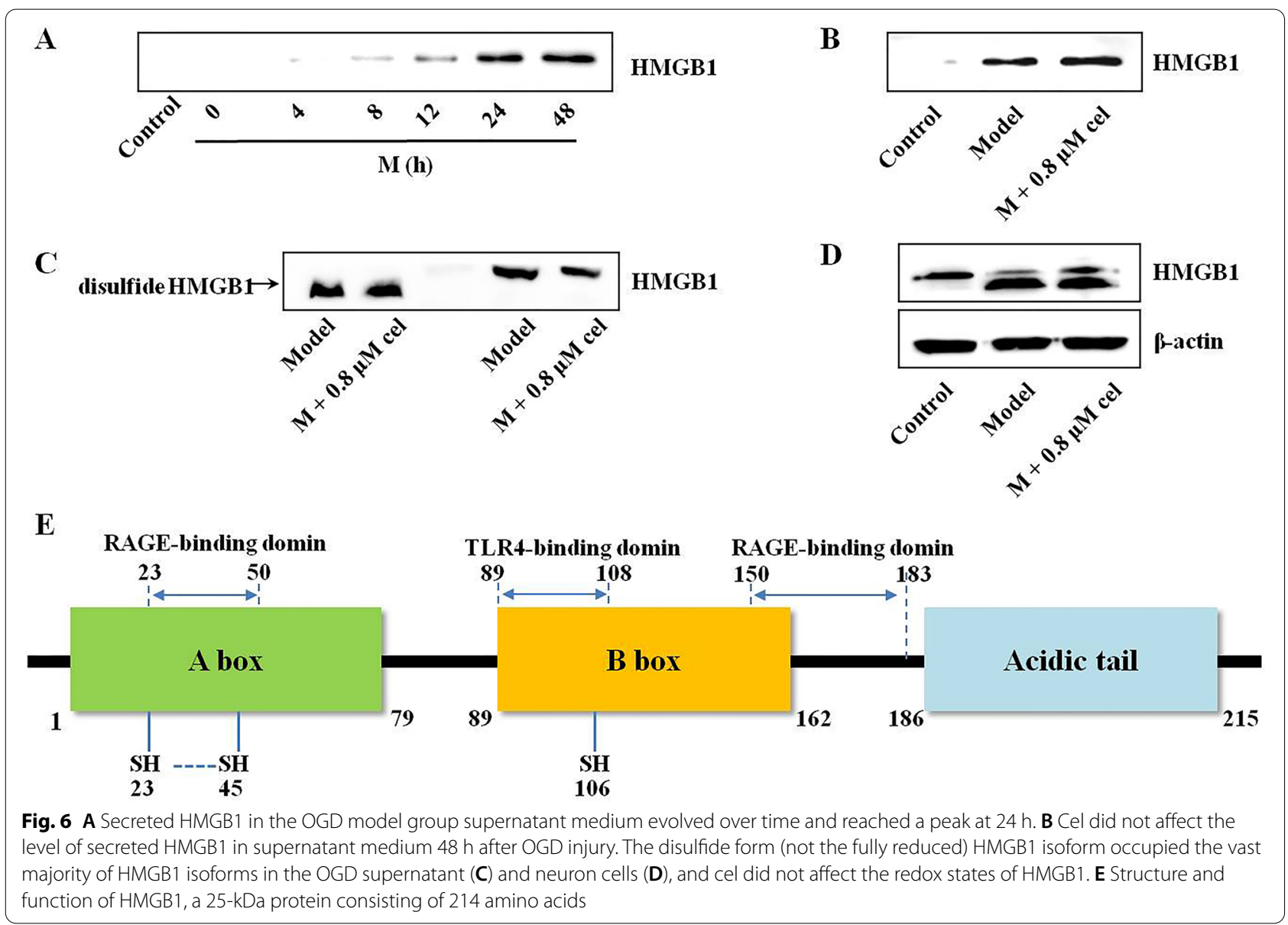

\section{Cel remarkably blocked the cytokine activity of HMGB1 and $B$ box}

Cel did not affect the expression or redox states of HMGB1 with or without OGD injury. In addition, previous research indicates that only disulfide bond HMGB1 isoform possesses cytokine activity [10]. Therefore, we mainly explored whether cel influenced the disulfide bond HMGB1 isoform induced increasing of TNF- $\alpha$ in RAW 264.7 cells. According to the description of the manual, the $50 \%$ effective concentration $\left(\mathrm{EC}_{50}\right)$ of HMGB1 for stimulating RAW 264.7 cells TNF- $\alpha$ production was $0.7855-0.8342 \mu \mathrm{g} / \mathrm{mL}$. Therefore, we chose $0.8 \mu \mathrm{g} / \mathrm{mL}$ HMGB1 to induce the secretion of TNF- $\alpha$ in RAW 264.7 cells. As shown in Fig. 8A, $0.8 \mu \mathrm{g} / \mathrm{mL}$ of HMGB1 increased TNF- $\alpha$ secretion more obviously than the control group in RAW 264.7 cells. In contrast, $0.1 \mu \mathrm{M}$ or $0.05 \mu \mathrm{M}$ cel $+0.8 \mu \mathrm{g} / \mathrm{mL}$ HMGB1 apparently decreased TNF- $\alpha$ secretion. Recombinant human HMGB1 B box $(0.02 \mu \mathrm{g} / \mathrm{mL}$ or $0.2 \mu \mathrm{g} / \mathrm{mL})$ increased TNF- $\alpha$ secretion more obviously than the control group, and cel $\left(1 \times, 10^{-6} \mu \mathrm{mol}\right.$ or $10^{-5} \mu \mathrm{mol}$, equimolar with B box) decreased TNF- $\alpha$ secretion apparently in RAW
264.7 cells (Fig. 8B). According to the published literature, TLR4 is the only receptor of HMGB1 that produces cytokines by binding to the B box Cys 106 [35]. Then, we utilized a recombinant human $B$ box and B box-cel $(1 \times$ or $5 \times$, cel was equimolar with or five times molar of B box) complex to verify that cel obviously blocked the binding of TLR4 and RAGE receptors to the B box (Fig. 8C). In conclusion, cel remarkably blocked the cytokine activity of HMGB1 and B box by directly binding to them to block the combination of inflammatory receptors.

\section{Discussions}

Our studies demonstrated the following: (1) cel exhibited a neuroprotective effect against cerebral I/R injury in vitro and in vivo; (2) cel directly bound to HMGB1 protein; (3) cel did not affect the expression of HMGB1, although it increased HSP70 and decreased NF-kB p65 expression to exert a neuroprotective effect in vitro and in vivo; (4) cel bound to Cys 106 of the disulfide bond HMGB1 isoform or Cys 23, 45, 106 of the fully reduced HMGB1 isoform; (5) cel scavenged the overproduced TNF- $\alpha$ induced by the disulfide bond HMGB1 isoform 


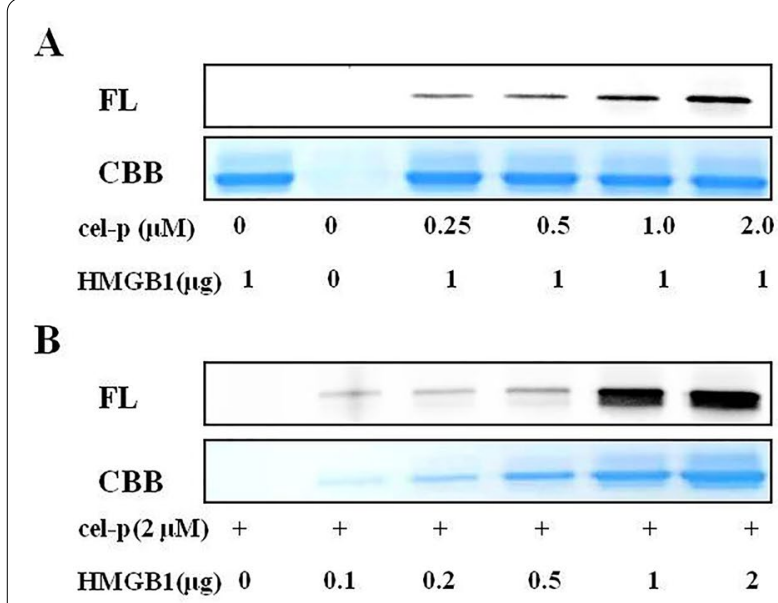

E

HMGB1 $1 \mu$ g/group

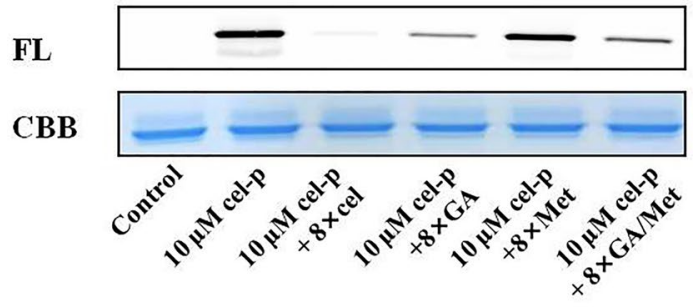

G

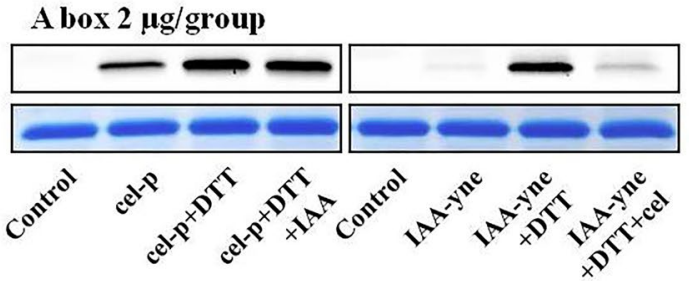

C

HMGB1 $1 \mu \mathrm{g} /$ group

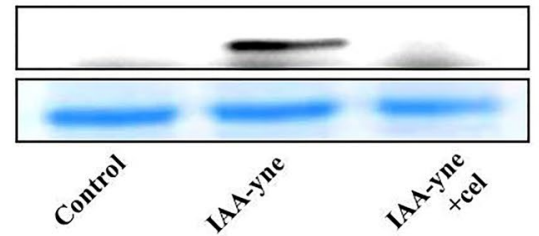

FL CBB

D

HMGB1 $1 \mu \mathrm{g} /$ group

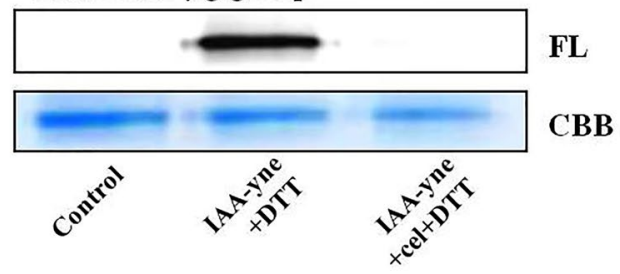

$\mathbf{F}$

Neuronal cell lysates

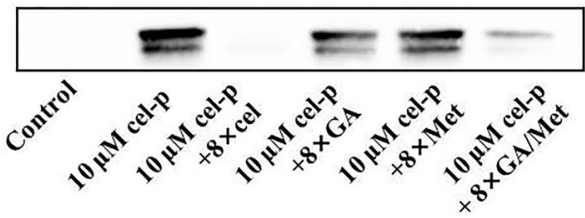

HMGB1

B box $2 \mu$ g/group

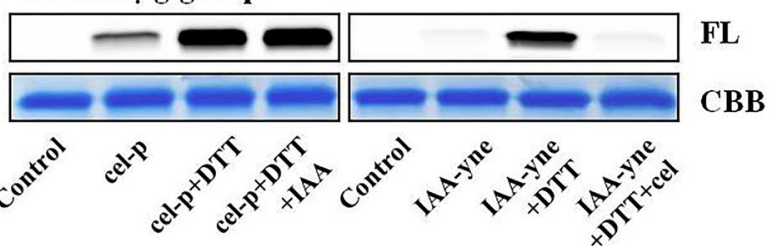

Fig. 7 A, B Cel exhibited strong combining ability with HMGB1 protein in a concentration-dependent manner. C, D Cel almost completely competed for the binding of IAA-yne with HMGB1, and DTT reduced HMGB1. E, F The binding ability of cel to the HMGB1 protein was stronger than that of GA and Met. G Cel could bind to other sites of HMGB1 in addition to Cys 23, 45 and 106

and B box; and (6) cel exerted an anti-inflammatory effect by binding to the $\mathrm{B}$ box to block the combination of receptors TLR4 and RAGE with the HMGB1 B box. Taken together, our findings suggested that the neuroprotective action of cel for ischemia stroke was partly due to its inhibition of neuroinflammation through upregulating HSP70 and downregulating NF-kB p65 expression and directly binding with HMGB1 protein. The specific experimental process is shown in Fig. 9.

With the maturation of mass spectrometry-based proteomics technology, stable isotope labels have been widely used in research on the biomarkers for diseases and drug targets through quantitative measurements of relative or absolute protein amounts in healthy versus disease states [36]. TMT reagents are commercially available and widely applied isobaric tags that allow multiplexing of up to 10 samples with high-resolution instruments and a range of sample types applicable [37]. TMT isobaric labeling could simultaneously identify and quantify complex protein mixture components with the key workflow of sample denaturation, digestion, isobaric tagging of tryptic peptides, fractionation, mass spectrometric analysis, and data processing [38, 39]. First, we verified that cel retained its biological activity after introducing biorthogonal reaction groups. Cel exhibited a neuroprotective effect against ischemia stroke in vitro and in vivo. With the aid of cel-p, TMT labeling, and LC-MS/MS technologies, we identified 1405 proteins in the cel-p target recognition experiment, and 120 were highly reliable. HMGB1 was identified as a direct binding protein of cel with fairly high credibility (Fig. 4).

CETSA is a label-free biophysical technique for studies of target engagement in cells and tissues based on ligand binding that affects protein stability and cellular studies 


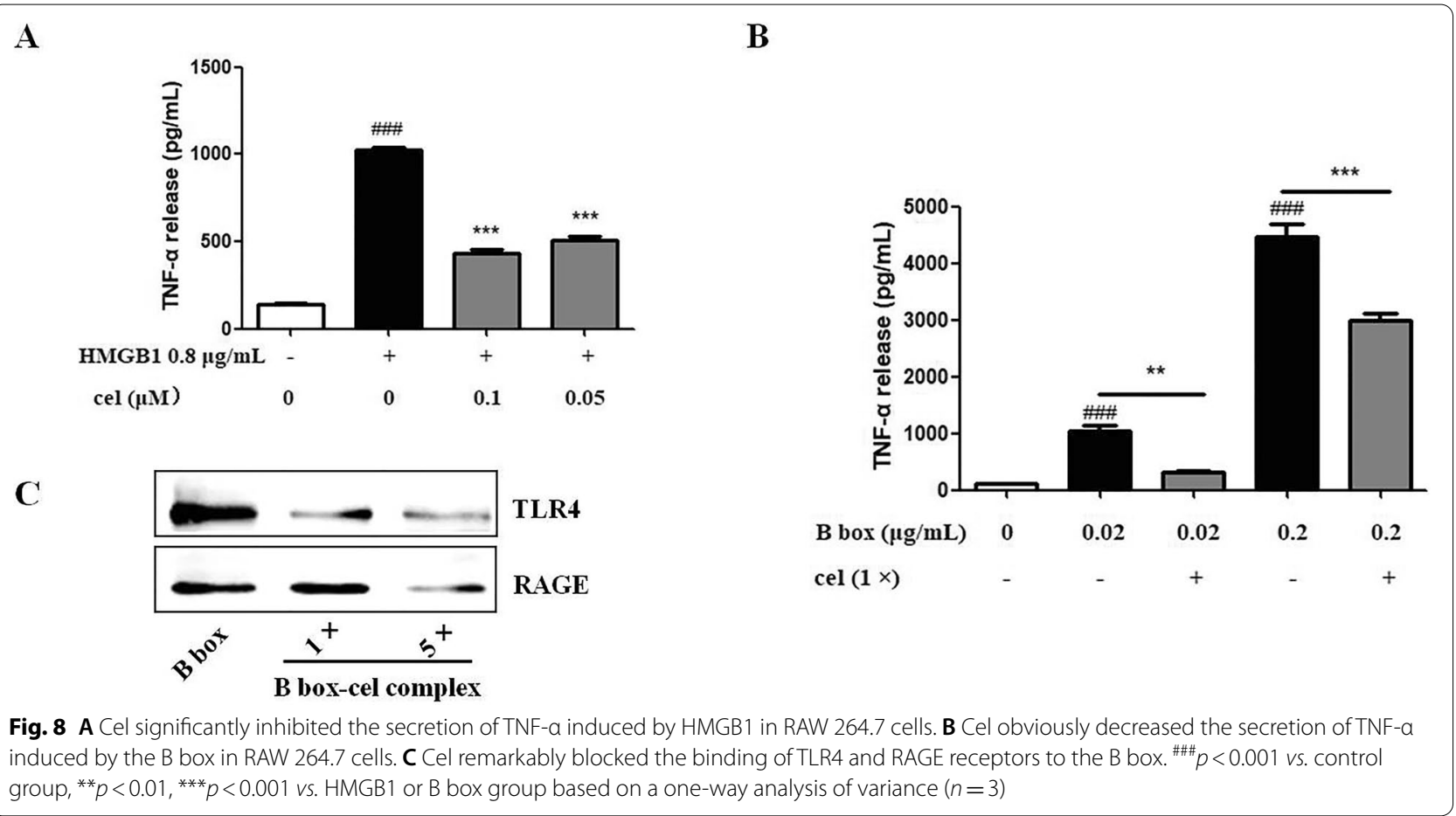

of protein redox modulations [40]. Generally, many proteins unfold after heating and precipitate rapidly in cells and drug-binding proteins can stabilize proteins and reduce their degradation with increasing temperature compared with untreated cells [41]. CETSA based on immunoassay (such as WB, proximity ligation assays, and mass spectrometry) detection is a hot technique for validating ligand binding of drugs to proteins in lysates, cells, and tissues, and it is based on measuring the protein melting curve changes after different heating steps and quantifying the amount of remaining soluble protein $[41,42]$. We investigated whether cel combined with and stabilized HMGB1 in cell lysate samples subjected to temperatures from 37 to $82{ }^{\circ} \mathrm{C}$. The results showed that compared with the DMSO-treated control group, the cel-treated group significantly stabilized HMGB1 and decreased its degradation with increasing temperature (Fig. 4E, F).

HMGB1 is highly expressed in the nucleus of multiple cell types, and the redox states of intracellular and extracellular HMGB1 are dynamic and mainly related to Cys 23, 45, and 106. The disulfide bond HMGB1 isoform (Cys 106 in thiol and Cys 23, 45 form disulfide bond) is required for the TLR4/MD-2 interaction to induce TNF release and NF- $\kappa B$ activation [10]. HMGB1 can be released by passive or active secretion via multiple pathways. Passive release of HMGB1 occurs rapidly during primary necrosis with the fully reduced or disulfide bond isoforms or nuclear retention and passive release during cell apoptosis secondary necrosis with a mainly fully oxidized isoform (sulfonyl HMGB1). Active secretion occurs in the late stage of pyroptosis with posttranslational modification and mainly occurs with the disulfide bond isoform [12]. Previous studies showed that cel significantly suppressed the HMGB1/NF- $\mathrm{KB}$ pathway to alleviate inflammatory pain, exhibited a neuroprotective effect in transient global cerebral $I / R$, and inhibited HMGB1 expression to decrease myocardial I/R injury [8, $43,44]$. In contrast to previous studies, the peak expression of HMGB1 was not detected in the model group and cel did not affect the expression of HMGB1. The results of this experiment may be related to the type of cells we selected. Because mammalian neurons are terminally differentiated, postmitotic cells and isolated primary rat cortical neurons have little ability to divide and proliferate in vitro in the absence of inducers [45]. The WB results for the neuron cells culture medium supernatant demonstrated that primary neurons suffering from OGD injury mainly actively secreted the disulfide bond HMGB1 isoform and the formation of disulfide bond could hardly be prevented by cel (Fig. 6). Plasma HMGB1 rapidly increases and acts as a proinflammatory cytokine to activate microglia, aggravate excitotoxicityinduced neuronal death, and aggravate brain injury during the acute damaging phase of ischemia insult $[46,47]$. Early HMGB1 translocation and release occurs mostly in 


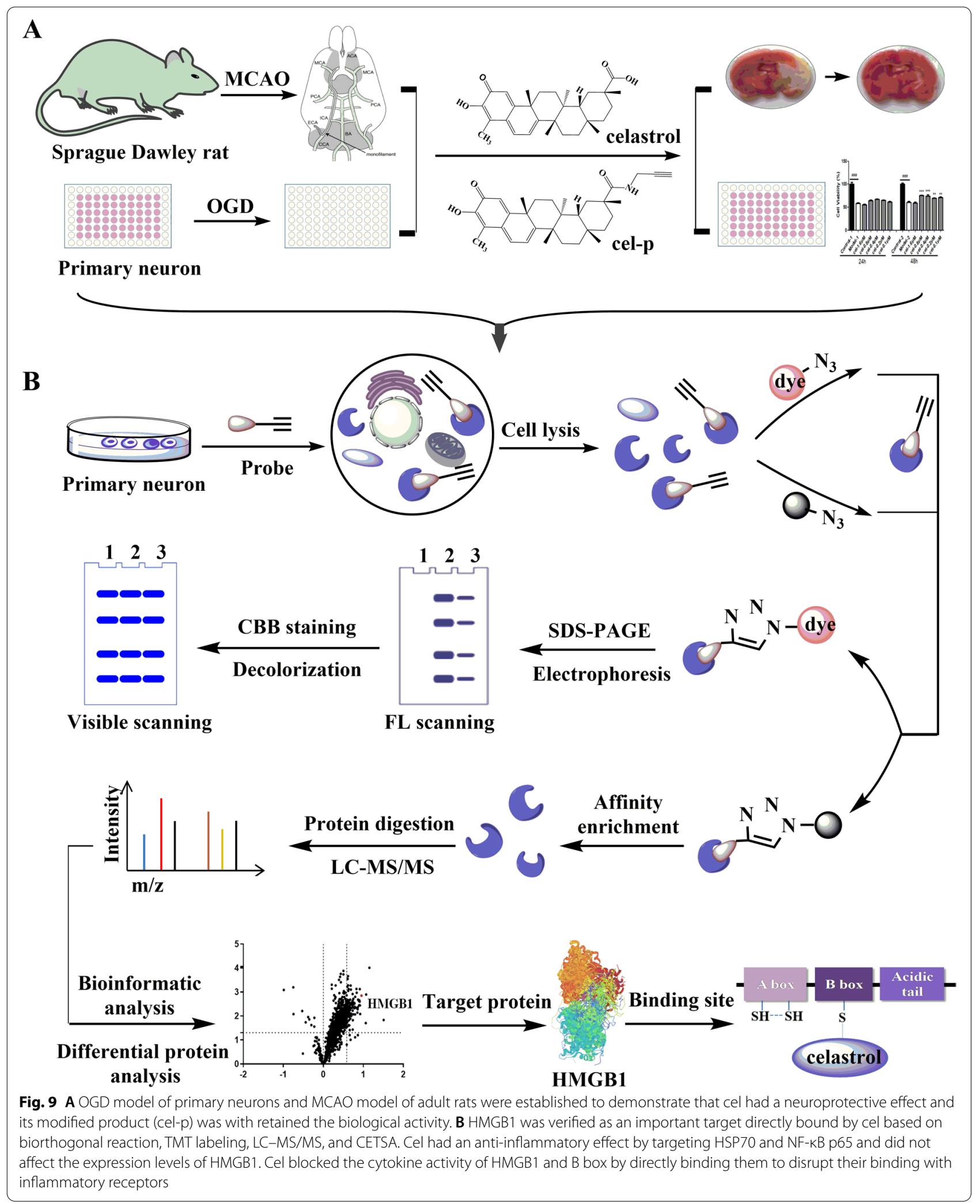


injured neurons and acts as a proinflammatory cytokine by interacting with receptors of RAGE, TLR2, and TLR4 [48]. High levels of HMGB1 in the serum and cerebrospinal fluid (CSF) are related to the severity of animal ischemia brain damage. In addition, HMGB1 in the serum of lipopolysaccharide (LPS)-administered MCAO animals was upregulated and mainly associated with the disulfide bond type [49]. Blockade of HMGB1 with antagonists has been verified as an effective treatment strategy for animal stroke models, including GA [50], HMGB1 A box, and anti-HMGB1 monoclonal antibody [51]. Previous studies demonstrated that peripheral disulfide bond HMGB1 isoform produced more obvious pronociceptive activity than all-thiol HMGB1 isoform by activating TLR4 rather than RAGE [52]. Here, we confirmed that cel did not affect the secretion, redox states, or expression of HMGB1 in either normal neurons or OGDexposed neurons. Apart from binding with Cys, cel also occupied other sites of HMGB1. Considering that only the disulfide bond HMGB1 isoform has cytokine properties, we focused on the effect of cel on disulfide bond HMGB1 isoform. Cys106 is the main binding site of the TLR4 receptor to HMGB1 to exert cytokine activity. In our research, cel directly bound to the HMGB1 A and B boxes and blocked the binding of the HMGB1 B box to its receptors TLR4 and RAGE, which resulted in inflammatory activity loss. Cel disrupted the TNF- $\alpha$-inducing capacity of HMGB1 and B box in RAW 264.7 cells. Therefore, cel was directly binding to HMGB1 protein to inhibit its inflammatory activity rather than reducing its secretion or changing its redox activity. In addition, cel exerted anti-inflammatory effects in cerebral $I / R$ injury by targeting HSP70 and NF-кB p65.

Although cel and its numerous derivatives exhibit potential therapeutic effects against various diseases, none of them have been approved for clinical use due to their toxic effects, low solubility, and narrow therapeutic dose range [53]. Therefore, identifying a method of resolving the toxicity of cel and improving its efficacy represents the next research direction. In addition, a growing body of evidence supports the idea that inflammation plays different roles in different stages of stroke [54]. HMGB1 shows different activities according to its redox modifications and may play a more complex role in ischemia stroke, which remains to be explored. In addition to cytokine activity, HMGB1 also exerts beneficial effects in axonal regeneration, endothelial activation, angiogenesis, neurovascular repair, and remodeling $[11,55]$. Therefore, it is necessary to carefully consider whether to promote or inhibit HMGB1 in different stages of stroke.

\section{Conclusions}

In summary, we performed a proteome-wide investigation of direct cellular protein binding targets of cel in primary rat cortical neurons and identified 120 targets with fairly high credibility through a quantitative chemical proteomics approach. The present study demonstrated the neuroprotective effect of cel against cerebral I/R injury by targeting HSP70 and NF- $\mathrm{kB}$ p65 and disrupting the cytokine activity of the disulfide bond HMGB1 isoform in a primary neurons OGD model and an adult rats MCAO model. The findings presented here may provide a potential therapeutic direction for ischemia stroke therapy. By directly binding to the HMGB1 B box, cel blocked the binding of the TLR4 and RAGE receptors with the B box, which promoted anti-inflammatory activity. To the best of our knowledge, this is the first study to evaluate the direct binding of cel to HMGB1. We hope that these data and findings from the present study could provide guidance for the clinical use of cel in the future.

\begin{abstract}
Abbreviations
OGD: Oxygen-glucose deprivation; MCAO: Middle cerebral artery occlusion; TMT: Tandem mass tags; CETSA: Cellular thermal shift assay; TEAB: Tetraethylammonium bromide; WB: Western blotting; IF: Immunofluorescence; Cys: Cysteine; HMGB1: High mobility group protein 1; DAMP: Damage-associated molecular pattern; RAGE: Receptor for advanced glycation endproducts; TLR: Toll-like receptor; TNF: Tumor necrosis factor; cel: Celastrol; cel-p: Celastrol probe; eda: Edaravone; LC-MS/MS: Liquid chromatography-tandem mass spectrometry; DMEM: Dulbecco's modified Eagle medium; FBS: Fetal bovine serum; DMSO: Dimethylsulfoxide; r.t.: Room temperature; I/R: Ischemiareperfusion; i.p.: Intraperitoneal injection; i.v.: Intravenous injection; SDS-PAGE: Sodium dodecyl sulfate-polyacrylamide gel electrophoresis; IAA: Iodoacetamide; IAA-yne: N-Hex-5-ynyl-2-iodoacetamide; LPS: Lipopolysaccharide; CCK-8: Cell counting kit-8; CBB: Coomassie brilliant blue; ICA: Internal carotid artery; ECA: External carotid artery; CCA: Common carotid artery; $I_{50}: 50 \%$ Inhibiting concentration; $\mathrm{EC}_{50}$ : 50\% Effective concentration; GA: Glycyrrhetinic acid; Met: Metformin; TTC: 2, 3, 5-Triphenyltetrazolium chloride; DTT: Dithiothreitol; CSF: Cerebrospinal fluid; IPTG: Isopropyl-D-1-thiogalactopyranoside.
\end{abstract}

\section{Supplementary Information}

The online version contains supplementary material available at https://doi. org/10.1186/s12974-021-02216-w.

Additional file 1. Supplementary Table S1.

\section{Acknowledgements}

We thank the Artemisinin Research Center, China Academy of Chinese Medical Sciences for use of their facility.

\section{Authors' contributions}

NM and JW designed the experiments; $\mathrm{DL}$ and PL performed the experiments; QZ, PG, YZ, and JZ assisted with experiments; NM analyzed the data and contributed analysis tools; DL wrote the manuscript; NM, LG, QG, and XC revised the manuscript. The authors read and approved the final manuscript. 


\section{Funding}

We gratefully acknowledge financial support from the National Key Research and Development Program of China (2020YFA0908000); the National Natural Science Foundation of China (81903588, 81803456, 81702580, 82074098, 81841001, 81903866 and 81803389); the CACMS Innovation Fund (Cl2021A05101); the Fundamental Research Funds for the Central public welfare research institutes (ZZ13-ZD-07, ZZ14-YQ-050, ZZ14-YQ-051, ZZ14ND-010 and ZZ15-ND-10).

\section{Availability of data and materials}

The datasets and materials supporting the conclusions of this article are included within the article.

\section{Declarations}

\section{Ethics approval and consent to participate}

All experiments animal operations meet the requirements of the Beijing Administration Rule of Laboratory Animal and were approved by the Animal Experimental Ethics Review Committee of the Institute of Basic Research for Chinese Medicine, China Academy of Chinese Medical Sciences.

\section{Consent for publication}

Not applicable.

\section{Competing interests}

The authors declare that there are no conflicts of interest.

\section{Author details}

${ }^{1}$ Artemisinin Research Center, and Institute of Chinese Materia Medica, China Academy of Chinese Medical Sciences, Beijing 100700, China. ${ }^{2}$ School of Biopharmacy, China Pharmaceutical University, Nanjing 210009, China. ${ }^{3}$ School of Pharmacy, Jinan University, Guangzhou 510632, China. ${ }^{4}$ Central People's Hospital of Zhanjiang, Zhanjiang, China. ${ }^{5}$ Guangdong Provincial Key Laboratory of New Drug Screening, School of Pharmaceutical Sciences, Southern Medical University, Guangzhou 510515, China. ${ }^{6}$ Department of Physiology, School of Preclinical Medicine, Guangxi Medical University, Nanning 530021, China. ${ }^{7}$ Key Laboratory of Prevention and Treatment of Cardiovascular and Cerebrovascular Diseases, Ministry of Education, Gannan Medical University, Ganzhou, China. ${ }^{8}$ Department of Urology, The Second Clinical Medical College of Jinan University, Shenzhen People's Hospital, 518020 Shenzhen, China.

Received: 13 April 2021 Accepted: 12 July 2021

Published online: 09 August 2021

\section{References}

1. Zhang Y, Mao X, Li W, Chen W, Wang X, Ma Z, Lin N. Tripterygium wilfordii: an inspiring resource for rheumatoid arthritis treatment. Med Res Rev. 2020:41:1337-74

2. Yizhi, Chen, Zhixiang, Gong, Xiangmei, Chen, Li, Tang, Xuezhi, Zhao. Tripterygium wilfordii Hook F (a traditional Chinese medicine) for primary nephrotic syndrome. Cochrane Database Syst Rev. 2013;(8). Art. No.:CD008568

3. Lu Y, Liu Y, Zhou J, Li D, Gao W. Biosynthesis, total synthesis, structural modifications, bioactivity, and mechanism of action of the quinonemethide triterpenoid celastrol. Med Res Rev. 2021;41:1022-60.

4. Xu S, Feng Y, He W, Xu W, Xu W, Yang H, Li X. Celastrol in metabolic diseases: progress and application prospects. Pharmacol Res. 2021:167:105572.

5. Li J, Hao J. Treatment of neurodegenerative diseases with bioactive components of Tripterygium wilfordii. Am J Chin Med. 2019;47:769-85.

6. Jiang M, Liu X, Zhang D, Wang Y, Hu X, Xu F, Jin M, Cao F, Xu L. Celastrol treatment protects against acute ischemic stroke-induced brain injury by promoting an IL-33/ST2 axis-mediated microglia/macrophage M2 polarization. J Neuroinflammation. 2018;15:78.

7. Li Y, He D, Zhang X, Liu Z, Zhang X, Dong L, Xing Y, Wang C, Oiao H, Zhu $C$, Chen Y. Protective effect of celastrol in rat cerebral ischemia model: down-regulating p-JNK, p-c-Jun and NF-KB. Brain Res. 2012;1464:8-13.
8. Zhang B, Zhong Q, Chen X, Wu X, Sha R, Song G, Zhang C, Chen X. Neuroprotective effects of celastrol on transient global cerebral ischemia rats via regulating $\mathrm{HMGB1/NF-KB}$ signaling pathway. Front Neurosci. 2020;14:847.

9. Maida C, Norrito R, Daidone M, Tuttolomondo A, Pinto A. Neuroinflammatory mechanisms in ischemic stroke: focus on cardioembolic stroke, background, and therapeutic approaches. Int J Mol Sci. 2020;21:6454.

10. Yang $\mathrm{H}$, Antoine $\mathrm{D}$, Andersson U, Tracey K. The many faces of HMGB1: molecular structure-functional activity in inflammation, apoptosis, and chemotaxis. J Leukoc Biol. 2013;93:865-73.

11. Singh V, Roth S, Veltkamp R, Liesz A. HMGB1 as a key mediator of immune mechanisms in ischemic stroke. Antioxid Redox Signal. 2016;24:635-51.

12. Harris $H$, Andersson U, Pisetsky D. HMGB1: a multifunctional alarmin driving autoimmune and inflammatory disease. Nat Rev Rheumatol. 2012:8:195-202.

13. Venereau E, Casalgrandi M, Schiraldi M, Antoine D, Cattaneo A, De Marchis F, Liu J, Antonelli A, Preti A, Raeli L, et al. Mutually exclusive redox forms of HMGB1 promote cell recruitment or proinflammatory cytokine release. J Exp Med. 2012;209:1519-28.

14. Yang $\mathrm{H}$, Wang $\mathrm{H}$, Ju Z, Ragab A, Lundbäck P, Long W, Valdes-Ferrer $\mathrm{S}$, He M, Pribis J, Li J, et al. MD-2 is required for disulfide HMGB1-dependent TLR4 signaling. J Exp Med. 2015;212:5-14.

15. Wang J, Gao L, Lee Y, Kalesh K, Ong Y, Lim J, Jee J, Sun H, Lee S, Hua Z, Lin Q. Target identification of natural and traditional medicines with quantitative chemical proteomics approaches. Pharmacol Ther. 2016;162:10-22.

16. Wang J, Zhang C, Chia W, Loh C, Li Z, Lee Y, He Y, Yuan L, Lim T, Liu M, et al. Haem-activated promiscuous targeting of artemisinin in Plasmodium falciparum. Nat Commun. 2015;6:10111.

17. Wang J, Tan X, Nguyen V, Yang P, Zhou J, Gao M, Li Z, Lim T, He Y, Ong C, et al. A quantitative chemical proteomics approach to profile the specific cellular targets of andrographolide, a promising anticancer agent that suppresses tumor metastasis. Mol Cell Proteomics. 2014;13:876-86.

18. Wang J, Zhang J, Zhang C, Wong Y, Lim T, Hua Z, Liu B, Tannenbaum S, Shen H, Lin Q. In situ proteomic profiling of curcumin targets in HCT116 colon cancer cell line. Sci Rep. 2016;6:22146.

19. Wang J, Zhang C, Zhang J, He Y, Lee Y, Chen S, Lim T, Ng S, Shen H, Lin Q. Mapping sites of aspirin-induced acetylations in live cells by quantitative acid-cleavable activity-based protein profiling (QA-ABPP). Sci Rep. 2015:5:7896.

20. Chen T, Chen S, Wang D, Hung H. The cholinergic signaling responsible for the expression of a memory-related protein in primary rat cortical neurons. J Cell Physiol. 2016;231:2428-38.

21. Yu Z, Liu N, Li Y, Xu J, Wang X. Neuroglobin overexpression inhibits oxygen-glucose deprivation-induced mitochondrial permeability transition pore opening in primary cultured mouse cortical neurons. Neurobiol Dis. 2013;56:95-103.

22. Cheng K, Lee J, Hao P, Yao S, Ding K, Li Z. Tetrazole-based probes for integrated phenotypic screening, affinity-based proteome profiling, and sensitive detection of a cancer biomarker. Angew Chem Int Ed Engl. 2017:56:15044-8.

23. Ma N, Hu J, Zhang Z, Liu W, Huang M, Fan Y, Yin X, Wang J, Ding K, Ye W, Li Z. H2-Azirine-based reagents for chemoselective bioconjugation at carboxyl residues inside live cells. J Am Chem Soc. 2020;142:6051-9.

24. Liu DD, Zou C, Zhang J, Gao P, Wang J. Target Profiling of an Anticancer Drug by an In Situ Approach. 2021.

25. Hengst J, Dick T, Smith C, Yun J. Analysis of selective target engagement by small-molecule sphingosine kinase inhibitors using the Cellular Thermal Shift Assay (CETSA). Cancer Biol Ther. 2020;21:841-52.

26. Kobayashi Y, Kanesaki Y, Tanaka A, Kuroiwa H, Kuroiwa T, Tanaka K. Tetrapyrrole signal as a cell-cycle coordinator from organelle to nuclear DNA replication in plant cells. Proc Natl Acad Sci USA. 2009;106:803-7.

27. Zhang Z, Liu D, Jiang J, Song X, Zou X, Chu S, Xie K, Dai J, Chen N, Sheng L, Li Y. Metabolism of IMM-H0O4 and its pharmacokinetic-pharmacodynamic analysis in cerebral ischemia/reperfusion injured rats. Front Pharmacol. 2019;10:631.

28. Zuo W, Zhang W, Han N, Chen N. Compound IMM-H004, a novel coumarin derivative, protects against CA1 cell loss and spatial learning impairments resulting from transient global ischemia. CNS Neurosci Ther. 2015;21:280-8. 
29. Salminen A, Lehtonen M, Paimela T, Kaarniranta K. Celastrol: molecular targets of Thunder God Vine. Biochem Biophys Res Commun. 2010;394:439-42.

30. Zhao Y, Zhao H, Lobo N, Guo X, Gentleman S, Ma D. Celastrol enhances cell viability and inhibits amyloid- $\beta$ production induced by lipopolysaccharide in vitro. J Alzheimers Dis. 2014;41:835-44.

31. Paimela T, Hyttinen J, Viiri J, Ryhänen T, Karjalainen R, Salminen A, Kaarniranta K. Celastrol regulates innate immunity response via NF-kB and Hsp70 in human retinal pigment epithelial cells. Pharmacol Res. 2011;64:501-8.

32. Boridy S, Le P, Petrecca K, Maysinger D. Celastrol targets proteostasis and acts synergistically with a heat-shock protein 90 inhibitor to kill human glioblastoma cells. Cell Death Dis. 2014;5:e1216.

33. Klaić L, Morimoto R, Silverman R. Celastrol analogues as inducers of the heat shock response. Design and synthesis of affinity probes for the identification of protein targets. ACS Chem Biol. 2012;7:928-37.

34. Zhang D, Chen Z, Hu C, Yan S, Li Z, Lian B, Xu Y, Ding R, Zeng Z, Zhang $X$, Su Y. Celastrol binds to its target protein via specific noncovalent interactions and reversible covalent bonds. Chem Commun (Camb). 2018:54:12871-4.

35. Yang $H$, Hreggvidsdottir H, Palmblad K, Wang H, Ochani M, Li J, Lu B, Chavan S, Rosas-Ballina M, Al-Abed Y, et al. A critical cysteine is required for HMGB1 binding to Toll-like receptor 4 and activation of macrophage cytokine release. Proc Natl Acad Sci USA. 2010;107:11942-7.

36. Chahrour O, Cobice D, Malone J. Stable isotope labelling methods in mass spectrometry-based quantitative proteomics. J Pharm Biomed Anal. 2015:113:2-20.

37. Ankney J, Muneer A, Chen X. Relative and absolute quantitation in mass spectrometry-based proteomics. Ann Rev Anal Chem (Palo Alto, Calif). 2018;11:49-77.

38. Westbrook J, Noirel J, Brown J, Wright P, Evans C. Quantitation with chemical tagging reagents in biomarker studies. Proteomics Clin Appl. 2015:9:295-300.

39. Thompson A, Schäfer J, Kuhn K, Kienle S, Schwarz J, Schmidt G, Neumann T, Johnstone R, Mohammed A, Hamon C. Tandem mass tags: a novel quantification strategy for comparative analysis of complex protein mixtures by MS/MS. Anal Chem. 2003;75:1895-904

40. Sun W, Dai L, Yu H, Puspita B, Zhao T, Li F, Tan J, Lim Y, Chen M, Sobota R, et al. Monitoring structural modulation of redox-sensitive proteins in cells with MS-CETSA. Redox Biol. 2019:24:101168.

41. Martinez Molina D, Nordlund P. The cellular thermal shift assay: a novel biophysical assay for in situ drug target engagement and mechanistic biomarker studies. Annu Rev Pharmacol Toxicol. 2016;56:141-61.

42. Dai L, Prabhu N, Yu L, Bacanu S, Ramos A, Nordlund P. Horizontal cell biology: monitoring global changes of protein interaction states with the proteome-wide cellular thermal shift assay (CETSA). Annu Rev Biochem. 2019;88:383-408.
43. Zhang X, Zhao W, Liu X, Huang Z, Shan R, Huang C. Celastrol ameliorates inflammatory pain and modulates HMGB1/NF-KB signaling pathway in dorsal root ganglion. Neurosci Lett. 2019;692:83-9.

44. Tong S, Zhang L, Joseph J, Jiang X. Celastrol pretreatment attenuates rat myocardial ischemia/ reperfusion injury by inhibiting high mobility group box 1 protein expression via the PI3K/Akt pathway. Biochem Biophys Res Commun. 2018;497:843-9.

45. Aranda-Anzaldo A, Dent M. Why cortical neurons cannot divide, and why do they usually die in the attempt? J Neurosci Res. 2017;95:921-9.

46. Kim J, Sig Choi J, Yu Y, Nam K, Piao C, Kim S, Lee M, Han P, Park J, Lee J. HMGB1, a novel cytokine-like mediator linking acute neuronal death and delayed neuroinflammation in the postischemic brain. J Neurosci. 2006;26:6413-21

47. Kim S, Lim C, Kim J, Shin J, Lee S, Lee M, Lee J. Extracellular HMGB1 released by NMDA treatment confers neuronal apoptosis via RAGE-p38 MAPK/ERK signaling pathway. Neurotox Res. 2011;20:159-69.

48. Qiu J, Nishimura M, Wang Y, Sims J, Qiu S, Savitz S, Salomone S, Moskowitz M. Early release of HMGB-1 from neurons after the onset of brain ischemia. J Cereb Blood Flow Metab. 2008;28:927-38.

49. Kim I, Lee H, Kim S, Lee H, Choi J, Han P, Lee J. Alarmin HMGB1 induces systemic and brain inflammatory exacerbation in post-stroke infection rat model. Cell Death Dis. 2018;9:426.

50. Kim S, Jin Y, Shin J, Kim I, Lee H, Park S, Han P, Lee J. Glycyrrhizic acid affords robust neuroprotection in the postischemic brain via antiinflammatory effect by inhibiting HMGB1 phosphorylation and secretion. Neurobiol Dis. 2012;46:147-56.

51. Nishibori M, Mori S, Takahashi H. Anti-HMGB1 monoclonal antibody therapy for a wide range of CNS and PNS diseases. J Pharmacol Sci. 2019:140:94-101.

52. Yamasoba D, Tsubota M, Domoto R, Sekiguchi F, Nishikawa H, Liu K, Nishibori M, Ishikura H, Yamamoto T, Taga A, Kawabata A. Peripheral HMGB1-induced hyperalgesia in mice: Redox state-dependent distinct roles of RAGE and TLR4. J Pharmacol Sci. 2016;130:139-42.

53. Hou W, Liu B, Xu H. Celastrol: progresses in structure-modifications, structure-activity relationships, pharmacology and toxicology. Eur J Med Chem. 2020;189:112081.

54. Jayaraj R, Azimullah S, Beiram R, Jalal F, Rosenberg G. Neuroinflammation: friend and foe for ischemic stroke. J Neuroinflammation. 2019;16:142.

55. Richard S, Sackey M, Su Z, Xu H, Pivotal neuroinflammatory and therapeutic role of high mobility group box 1 in ischemic stroke. Biosci Rep. $2017 ; 37$.

\section{Publisher's Note}

Springer Nature remains neutral with regard to jurisdictional claims in published maps and institutional affiliations.
Ready to submit your research? Choose BMC and benefit from:

- fast, convenient online submission

- thorough peer review by experienced researchers in your field

- rapid publication on acceptance

- support for research data, including large and complex data types

- gold Open Access which fosters wider collaboration and increased citations

- maximum visibility for your research: over 100M website views per year

At BMC, research is always in progress.

Learn more biomedcentral.com/submissions 